\title{
Health Effects Related to Wind Turbine Sound, Including Low-Frequency Sound and Infrasound
}

\author{
Irene van $\operatorname{Kamp}^{1}{ }_{(\mathbb{C})} \cdot$ Frits van den $\operatorname{Berg}^{2}(\mathbb{C}$
}

Received: 15 June 2017 / Accepted: 15 September 2017 / Published online: 23 October 2017

(C) Australian Acoustical Society 2017

\begin{abstract}
A narrative review of observational and experimental studies was conducted to assess the association between exposure to wind turbine sound and its components and health effects in the general population. Literature databases Scopus, Medline and Embase and additional bibliographic sources such as reference sections of key publications and journal databases were systematically searched for peer-reviewed studies published from 2009 to 2017 . For the period until early 2015 only reviews were included, while for the period between January 2015 and January 2017 all relevant publications were screened. Ten reviews and 22 studies met the inclusion criteria. Most studies examined subjective annoyance as the primary outcome, indicating an association between exposure levels and the percentage highly annoyed. Sound from wind turbines leads to a higher percentage of highly annoyed when compared to other sound sources. Annoyance due to aspects, like shadow flicker, the visual (in) appropriateness in the landscape and blinking lights, can add to the noise annoyance. There is no evidence of a specific effect of the low-frequency component nor of infrasound. There are indications that the rhythmic pressure pulses on a building can lead to additional annoyance indoors. Personal characteristics such as noise sensitivity, privacy issues and social acceptance, benefits and attitudes, the local situation and the conditions of planning a wind farm also play a role in reported annoyance. Less data are available to evaluate the effects of wind turbines on sleep and long-term health effects. Sleep disturbance as well as other health effects in the vicinity of wind turbines was found to be related to annoyance, rather than directly to exposure.
\end{abstract}

Keywords Health effects · Wind turbine sound $\cdot$ Infrasound $\cdot$ Low-frequency noise $\cdot$ Observational studies $\cdot$ Experimental studies

\section{Introduction}

Globally, the use of sustainable sources of energy such as biomass, water power, solar and wind energy is increasing in order to reduce the use of fossil fuel. Worldwide targets are set for an increase in sustainable energy. As a result, it can be expected that the number of wind farms will keep growing

Irene van Kamp

Irene.van.kamp@rivm.nl

1 National Institute for Public Health and the Environment, Netherlands, Antonie van Leeuwenhoeklaan 9, 3721 MA Bilthoven, The Netherlands

2 GGD Amsterdam Public Health Service, Nieuwe Achtergracht 100, 1018 WT Amsterdam, The Netherlands in the years to come and more people will have them in their immediate living environment. Most people have a positive attitude towards alternative energy sources; for example, in the Netherlands in $200690 \%$ of the population was positive about solar energy and $79 \%{ }^{1}$ was positive about wind energy. However, although the benefits at national and global level are recognized, viz. a reduction in atmospheric carbon dioxide concentration, at a local level people often oppose wind farm plans. The awareness of the consequences of a wind farm can lead to intense, and sometimes emotional discussions about the need for wind energy, the suitability of the area, the visual and aesthetic aspects and noise-related issues

\footnotetext{
1 Special Eurobarometer, Attitudes towards energy. European Commission (2006).
} 
are not uncommon. Health effects of living in the vicinity of the turbines are often part of the discussion. The association between wind turbines and human responses is a complex one, and many factors play a role in the public debate. At the local level attention is often focused on the potentially negative health effects of living near a wind turbine.

This paper addresses the state of the art regarding health effects related to wind turbine sound and is based on a manuscript prepared at the request of the Noise and NIR Division of the Swiss Federal Office for the Environment (Bundesamt für Umwelt). Although several excellent reviews on this topic have been published, we think it is worthwhile to publish this narrative review because several large studies have been completed after publication of the most recent meta-analysis [1]. Also, this review addresses the effects to living in the vicinity of wind turbines (WT's) in a broader physical and social context and includes the evidence for possible health effects of the low-frequency and infrasound components. And finally, we made an effort to write a text that is accessible for a broader audience.

In this text we use the word 'sound' when it refers to sound in a neutral sense. The sound of WT's is not always perceived as negative as the word 'noise' (meaning: unwanted sound) would suggest. The term WT noise is quite common but in our opinion only correct when it refers to negative effects, such as in 'noise annoyance'. When it does, we may also use the word 'noise'.

In line with the definition of health as 'a state of complete physical, mental, and social well-being and not merely the absence of disease or infirmity' of the World Health Organization (WHO) [2], noise annoyance and sleep disturbance are considered here as health effects [3] ${ }^{2}$ [4].

Because this review aims at a broad audience, it might be useful to explain briefly WT sound itself. We therefore start in Sects. 1.1 to 1.3 with an explanation of the sound produced by and heard from a wind turbine and what sound levels occur in practice. After a description of methods used in this review in Sects. 2 and 3 first summarizes the evidence from existing reviews. This is followed by a more detailed description of studies not covered in these reviews. In both parts the key issue is how sound from a wind turbine can affect people, especially neighbouring residents, and in what way and to what degree other factors are important to take into account. This is repeated in Sect. 4 for sound at (very) low frequencies that allegedly can affect people in other ways than 'normal' sound does. Here we use the term 'normal' sound casually when it is easily recognizable as sound and can be heard; this

\footnotetext{
2 Although high annoyance is not classified as a disease in the International Classification of Disease (ICD-9; ICD-10), it does affect the well-being of many people and therefore may be considered to be a health effect falling within the WHO definition of health.
}

does not include infrasound or low levels of other sound that are normally considered to be inaudible.

Our conclusions from reading and interpreting all the scientific information are summarized in Sect. 5 that concludes the main text.

\subsection{Sound Production and Character}

An overview of wind turbine sound sources can be found in a number of publications such as [5-8]. For the tall, modern turbines most sound comes from flowing air in contact with the wind turbine blades: aerodynamical sound. The most important contributions are related to the atmospheric turbulence hitting the blades (inflow turbulence sound) and air flowing at the blade surface (trailing edge sound).

- Turbulence at the rear or trailing edge of a blade is generated because the air flow at the blade surface develops into a turbulent layer. The frequency with the highest (audible) sound energy content is usually in the range of a few hundred $\mathrm{Hz}$ up to around $1000-2000 \mathrm{~Hz}$. At the blade tips conditions are somewhat different due to air flowing towards the tip, but this tip noise is very similar to trailing edge noise and usually not distinguished as a relevant separate source.

- Inflow turbulence is generated because the blade cuts through turbulent eddies that are present in the inflowing air (wind). This sound has a maximum sound level at around $10 \mathrm{~Hz}$.

- Thickness sound results from the displacement of air by a moving blade and is insignificant for sound production when the air flows smoothly around the blade. However, rapid changes in forces on the blade result in sudden sideways movements of the blade and sound pulses in the infrasound region. This leads to the typical wind turbine sound 'signature' of sound level peaks at frequencies between about $1-10 \mathrm{~Hz}$. These peaks cannot be heard, but can be seen in measurements.

Inflow turbulence sound is important in the low- and middlefrequency range, overlapping with trailing edge sound at medium and higher frequencies. As both are highly speed dependent, sound production is high where the speed is high and highest near the fast rotating tips of the blades. Wind turbine sound can sometimes be tonal, i.e. one can hear a specific pitch. This can be mechanical sound from the gear box and other devices in the turbine which was a relevant source for early turbines. Another possible source is an irregularity on a blade, but this is apparently rare and can be mended.

When the sound penetrates into a dwelling, the building construction will attenuate the higher frequencies better than the lower frequencies. As a result, indoor levels will be lower and the sound inside is of a lower pitch, as higher frequencies 
are more reduced than low frequencies. This is true for every sound coming from outside. Wind turbine sound changes over time. An important feature is the variation of the sound at the rhythm of the rotating blades. This variation in synchrony with the blade passing frequency is also called the amplitude modulation (AM) of the sound [6,9-12].

\subsection{Human Hearing}

Most environmental sounds with a level of $40 \mathrm{dBA}$ will approximately have the same loudness for human hearing because the A-weighting (that is implied by the A in $\mathrm{dBA}$ ) is based on the loudness curve of 40 phon (which equals $40 \mathrm{~dB}$ at $1000 \mathrm{~Hz}$ ). Such a low to moderate loudness is comparable with actual wind turbine sound levels at many residences near wind farms. Therefore, A-weighting should give a (nearly) correct estimate of the loudness of a sound. With hearing tests this was confirmed in the Japanese wind turbine sound study [13]. A-weighting is less correct at lower sound levels; application of A-weighting to low levels (roughly $<30 \mathrm{dBA}$ ) may allow for more low-frequency sound. Of course, this concerns sound levels that are already low and usually will comply with limits. It is because of the combination of our hearing capacities at different frequencies and the sound level of the different wind turbine sources that trailing edge sound is the most dominant sound when outside and not too far from a wind turbine. The sound will shift to lower frequencies at larger distances or indoors, and then inflow turbulent sound can be more important.

When a sound is 'subaudible', the level of that sound is below the hearing threshold and thus below the level it can be audible. Usually the 'normal' threshold (hearing threshold of young adults without hearing problems, according to the international standard ISO 326) is used. As there is a variation between individuals, the normal threshold is the hearing threshold separating the $50 \%$ best hearing from the $50 \%$ that hear less well. For an individual often that normal hearing threshold is taken as an indication, but for that person of course the individual hearing threshold is relevant. Hearing acuity may differ considerably between persons. Hearing generally deteriorates with age, but this is typically less so at lower frequencies when compared to higher frequencies.

\subsection{Sound Levels in Practice}

For a modern turbine, the maximum sound power level is in the range between 100 and $110 \mathrm{dBA}$. 'Sound power' is the total amount of sound radiated from a source. For a listener on the ground close to a turbine, the outdoor sound level will not be more than about $55 \mathrm{dBA}$. At residential locations this is often less and in most studies there are few people, if any, exposed to an average sound level of over $45 \mathrm{dBA}$. For a wind turbine, maximum sound levels are not much higher than average sound levels. For two turbine types in a temperate climate, it was shown that the sound level from these two types at high power is $1-3 \mathrm{~dB}$ above the sound level averaged over a long time [14].

Measurements on many types of modern wind turbines show that most sound energy is radiated at low and infrasound frequencies and less at higher frequencies (approximately $100-2000 \mathrm{~Hz}$ ). However, because of the lower sensitivity of human hearing at low frequencies, audibility is greater at the higher frequencies. In the last decades wind turbines have become bigger and onshore wind turbines now can have several megawatts (MW) electric power. $2 \mathrm{MW}$ turbines produce 9-10 dB more sound power when compared to $200 \mathrm{~kW}$ turbines $[15,16]$. Over time the amount of low-frequency sound $(10-160 \mathrm{~Hz})$ increases at nearly the same rate as the total sound level. Depending on what the reference situation is, this is somewhat less according to one author [15], somewhat more according to the other [16].

\subsection{Aspects Other than Sound}

Apart from sound, visual aspects, safety and vibrations related to wind turbines may also have an impact on the environment and the people living in it. Economic benefit, intrusion in privacy and acceptance of the wind turbines and other sources of disturbance are relevant to understand levels of annoyance. Also, personal and contextual aspects can determine the level of annoyance due to wind turbines.

\section{Method}

\subsection{Data Sources and Search}

This paper summarizes the present knowledge available about the association between wind turbine sound and health. It is based on several literature searches and reviews recently performed in the Netherlands $[17,18]$ and updated with literature until February 2017, using the same method. Some papers from the most recent conference on Wind Turbine Noise (May 2017) have also been added to the overview in Sect. 4.

For this review a systematic literature search was performed at three moments in time (2000-2012; 2012-2015; and 2015-2017) using the same protocol. Observational as well as experimental studies described in the peer review literature in the period between 2009 and 2017 were included. Language was restricted to German, English, French and Dutch. The databases Scopus, Medline and Embase (note: only 2015-2017) were searched because these studies do not appear in the available reviews yet and they are of high value as they build on earlier evidence. The search strategy is described in Table 1. 
Table 1 Key search terms and search profile
2

3

4

5

6

7

8

9

10

11

12

15

16

17

18
(Wind turbine* or wind farm* or windmill* or wind park* or wind power or wind energy).ti. (550)

Turbine noise*.tw. and wind/ (33)

(Power plants/ or energy-generating sources/ or electric power supplies/) and wind/ (187)

(Low frequency noise* or low frequency sound* or infrasound or infrasonic noise* or infrasonic sounds or infrasonic frequencies or low frequency threshold or (noise* adj4 low frequenc $\left.{ }^{*}\right)$ ).ti. (500)

1 or 2 or 3 or $4(1113)$

(Wind turbine* or wind farm* or windmill* or wind park* or wind power or wind energy).ab. (803)

(Low frequency noise* or low frequency sound* or infrasound or infrasonic noise* or infrasonic sounds or infrasonic frequencies or low frequency threshold or (noise* adj4 low frequenc*)).ab. (1487)

Noise*.ti. (26930)

(6 or 7$)$ and 8 (498)

(Impact or perception* or perceive* or health* or well-being or "quality of life" or syndrome*).ti. (1456358)

(Annoyance or annoying or annoyed or aversion or stress or complaints or distress or disturbance or adversely affected or concerns or worries or noise problems or noise perception or noise reception or noise sensitivity or (sensitivity adj3 noise) or sound pressure level* or sleep disturbance* or sleep quality or cognitive performance or emotions or anxiet* or attitude*).tw. (1260490)

(Social barrier* or social acceptance or popular opinion* or public resistance or (living adj4 vicinity) or (living adj4 proximity) or (residing adj4 vicinity) or (residing adj4 proximity) or living close or "living near" or residents or neighbors or neighbours).tw. (105942)

(Soundscape or landscape or visual annoyance or visual interference or visual perception or visual impact or visual preferences or visual assessment or visual effects or perceptual attribute*).tw. (41227)

(Effects adj4 population) or dose-response relationship* or exposure-response relationship* or dose response or exposure response or human response or health effects or health aspects or health outcome*).tw. (136924)

(Flicker or reflection).ti. (10980)

Environmental exposure/ or noise/ae or environmental pollution/ae (79725)

Loudness perception/ or psychoacoustics/ or auditory perception/ or auditory threshold/ or sensory thresholds/ or visual perception/ or motion perception/ (130572)

Sleep disorders/ or emotions/ or anger/ or anxienty/ or quality of life/ or epilepsy/ or attitude/ or affect/ or pressure/ or aesthetics/ or social environment/ or risk factors/ (1232239)

(Physiopathology or adverse effects).fs. (3235762)

Language: English or Dutch or French or German

Search period: 2009-2017

Duplicates removed

Exclude animals/not humans
We aimed to include low-frequency sound and infrasound in this review, but there are less publications and reviews specifically addressing this part of the spectrum. Also, the (alleged or studied) effects of infrasound and low-frequency sound are different from the effects of 'normal' sound. As a consequence, this topic is reviewed separately and is based on all relevant publications from the literature search (Fig. 1).

\subsection{Inclusion Criteria}

Only studies were included in which it was mentioned in the title, abstract or summary that the association was studied between the sound or noise of wind turbines and a reaction or effect concerning health or well-being. Also, studies addressing participation during the building process were accepted for review. This implied that the association between exposure to wind turbine (low-frequency) sound and annoyance, health, well-being or activity disturbance in the adult population was studied.

For a first selection the following criteria were used. Inclusion: papers address human health effects, perception, opinion, concern in relation to wind turbines. Exclusion: papers address non-human effects such as ecosystem effects, animals, papers solely about technical aspects of the wind turbines, papers regarding health effects of sound but not related to wind turbines. This resulted in total in 202 possi- 
Search for peer reviewed articles published between January 2009 and February 2017: 387 articles in Medline, Scopus and (since 2015) Embase

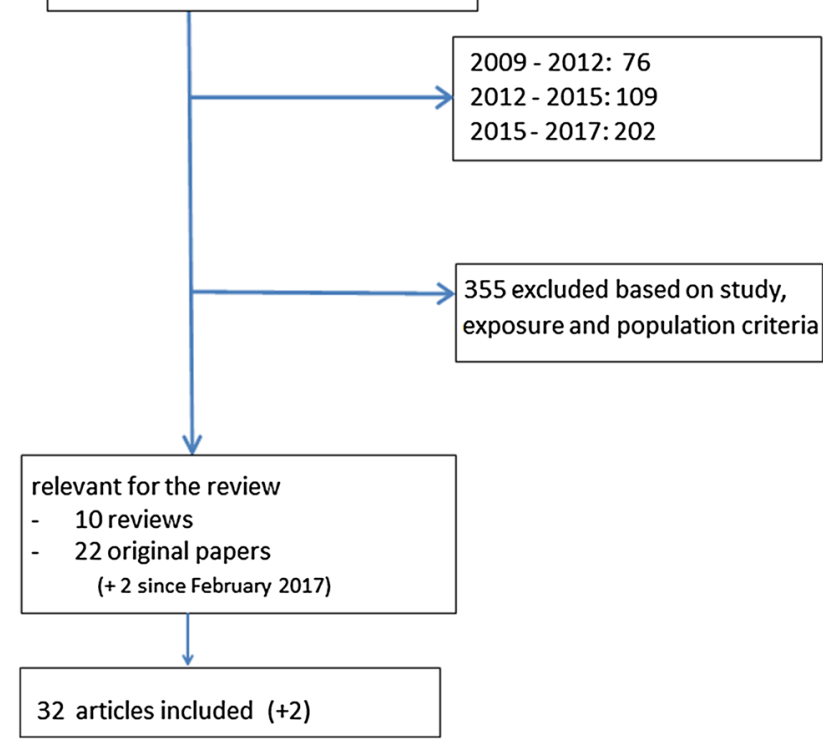

Fig. 1 Flowchart of selection process

bly relevant studies for the period between January 2015 and February 2017.

The papers for the period from January 2015 to February 2017 were grouped in seven categories: review, health effects, case studies, offshore, low-frequency sound/infrasound, visual aspects, social and not relevant. All reviews and health effects studies were included for full paper examination. All low-frequency sound/infrasound studies were examined for inclusion in the separate review. Offshore studies were a priori excluded; papers from the other categories were reconsidered after reading the abstracts.

Lastly, after full examination of the reviews and lowfrequency sound/infrasound and health effect papers by the two authors, a final decision was made about inclusion in this review.

\subsection{Procedure and Study Quality Assessment}

This review is primarily based on results from epidemiological studies at population level and smaller-scale laboratory experiments.

The results have been divided into three sections. The difference in material between both periods (up to and since 2015) resulted in two sections: first we review the reviews (Sect. 3.1), and then we review original studies most of which are from the second period (3.2). The effects of infrasound and low-frequency sound are summarized in a third part (Sect. 4).

The main results are summarized per outcome. For the key studies, the study design and outcomes are discussed in more detail. For this review primarily scientific publications are used, from both peer-reviewed journals and conference proceedings. In some cases results are discussed which were described in non-scientific ('grey') literature. Also, some publications are mentioned that are often used in the debate (discourse) about the risks of living in the vicinity of wind turbines.

As usual, all material from the selected literature has been read and analysed, but not necessarily included as reference, e.g. because the study was less relevant than originally thought or in case of doubling with other references (e.g. a conference paper and an article from the same authors and study). A meta-analysis on (part of) the data was not considered in the time frame of this assignment.

\section{Results}

Annoyance and sleep disturbance are the most frequently studied health effects of wind turbine sound as is also the case for sound from other sources. After a short explanation of the health effects addressed in the literature, the overall conclusions from key reviews are summarized. Then the main findings for annoyance, sleep disturbance and other health effects are described in more detail, sometimes referring to the underlying publications. The influence of personal, situational and contextual factors on these effects is also included. Then in Sect. 3.2 the most recent original studies (20152017) are described separately in more detail while following the same structure.

Effects that are mentioned as specific effects of infrasound and/or low-frequency sound are treated in Sect. 4.

\subsection{Evidence Until Early 2017: Reviews}

People can experience annoyance or irritation, anger or disturbance from wind turbine sound, or when they feel that their environmental quality and quality of life deteriorates due to the siting of wind turbines near their homes.

The number of publications on wind turbine sound and its health effects has increased considerably in the past 10 years, including peer-reviewed articles, conference papers and policy documents (Table 2).

A remarkable number of nineteen reviews were published in the period between 2009 and 2017. These include systematic reviews as well as policy preparing reviews. Some reviews were dismissed after reading the full text, since they were highly anecdotal, no health impact was estimated, incomplete or only concerned occupational exposure, etc. 


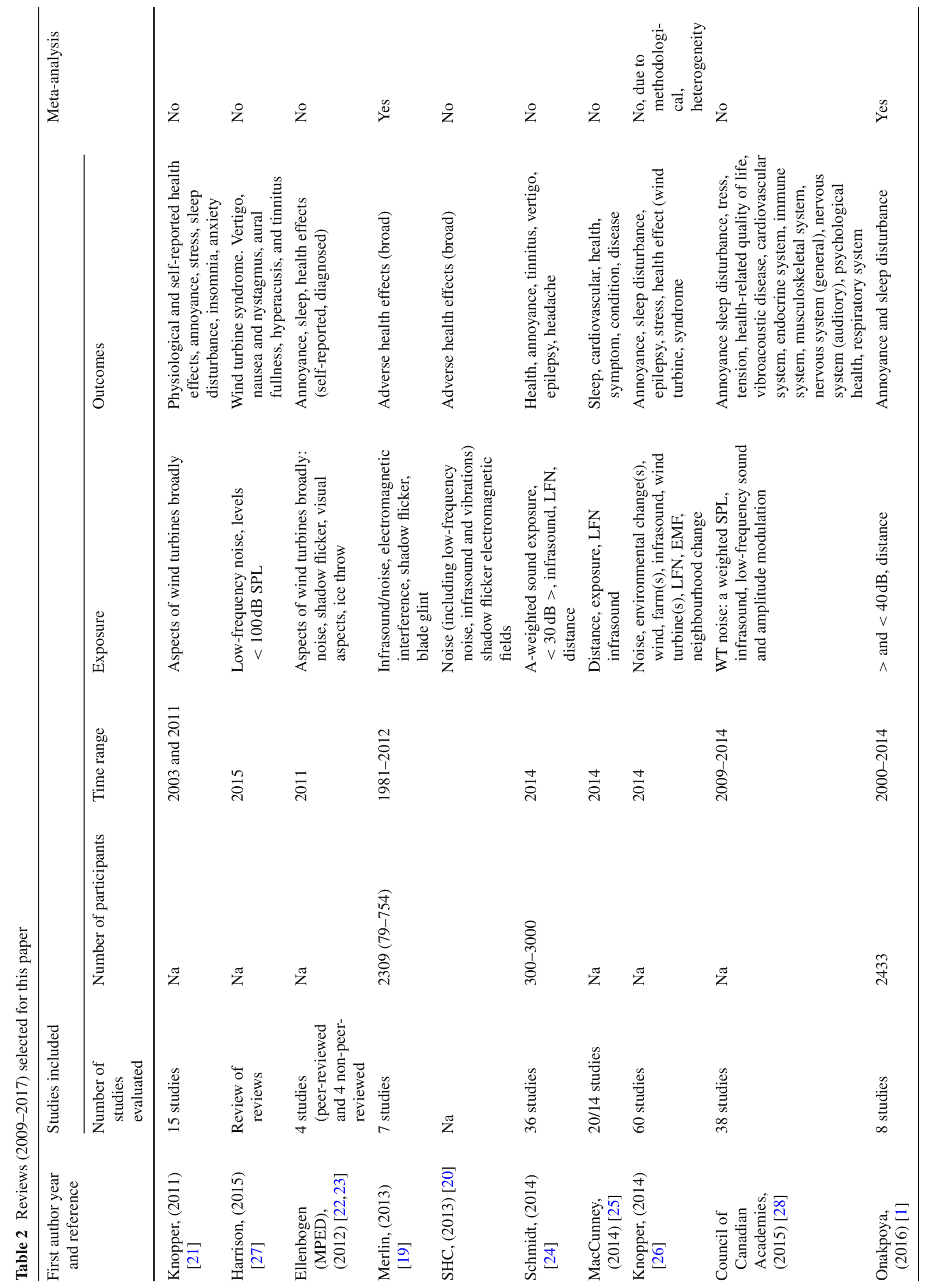


The remaining ten recent and leading reviews and policy documents (described in 11 manuscripts: [1,19-28] draw comparable conclusions about the health effects of wind turbine sound: in general, an association is found between annoyance and the level of wind turbine sound. Also, an association between sound level and sleep disturbance is considered plausible, even though a direct relation is uncertain because of the limited number of studies with sometimes contradictory results. Perceived stress is related to chronic annoyance or to the feeling that environmental quality and quality of life has diminished due to the placement of wind turbines, and there is sufficient evidence that stress can negatively affect people's health and well-being in people living in the vicinity of wind turbines [20].

Next to sound, vibration, shadow flicker, warning lights and other visual aspects have been examined in the reviews. There are no studies available yet about the long-term health effects. Such longitudinal studies (studies comparing the situation at different moments in time) might be useful to gain more insight in the causal pathways of the different factors. However, they can still only examine the strength of temporal associations across a range of relevant variables and to establish causal relations will remain problematic in this area.

Most recently, Onakpoya et al. [1] reanalysed the data from eight cross sectional studies, selected on strict quality requirements and including a total of 2433 participants. Effects considered were annoyance, sleep disturbance and quality of life. Evidence supports the earlier conclusion that there is an association between exposure to wind turbine sound and an increased frequency of annoyance and sleep problems, after adjustment for key variables as visual aspects, attitudes and background sound levels. The strength of evidence was the most convincing for annoyance, followed by sleep disturbance, when comparing participants at exposure levels below and above $40 \mathrm{~dB}$. The findings are in line with Schmidt and Klokker [24] and Janssen et al. [29]. In contrast to these authors, Merlin et al. [19] consider annoyance a response to wind turbines and not a (health) effect as such.

Personal and contextual factors can influence annoyance. There is consensus in the literature that visual aspects, attitudes towards wind turbines in the landscape and towards the people responsible for wind farms, the process around planning and construction and economic interest can all in their own way affect levels of annoyance. However, actual evidence for this is still limited.

The next sections will describe the state of the art in more detail per health effect. Note that the description is limited to the effects of wind turbine sound in the 'normal' frequency range. Findings from studies, addressing suggested specific impacts of the low-frequency component and infrasound distinct from 'normal' sound are summarized separately in Sect. 4.

\subsubsection{Noise Annoyance}

In many countries the assessment of the sound of wind turbines is based on average, A-weighted sound levels (see Sect. 1.2). It is generally accepted that annoyance from wind turbines occurs at lower levels than is the case for traffic or industrial sound. Based on Dutch and Swedish data, an exposure-effect relation was derived between calculated sound exposure levels expressed in Lden (day-evening-night level) and the percentage highly annoyed, for indoor as well as outdoor exposures. Later research in Japan and Poland have confirmed these results and obtained similar results $[30,31]$. The relation between wind turbine sound and annoyance can be compared with those for road, rail and aircraft sound. This comparison is presented in Fig. 2 where the 'aircraft Europe' data are from the European HYENA study [32], the wind turbine data are from Janssen et al. [29], and the other data are from Miedema and Vos [33] for industrial sound and from Miedema and Oudshoorn [34] for air, road and rail transportation sound. The more recent HYENA study has shown that at a number of big European airports noise annoyance has increased when compared to the older data from Miedema and Oudshoorn [34]. Figure 2 shows that sound from wind turbines leads to a higher percentage of highly annoyed people when compared to other sound sources. The relation resembles that of air traffic sound, but near airports there are higher sound levels and a correspondingly higher percentage of highly annoyed. The relations for transport sound in Fig. 2 have been derived for large numbers of persons from many countries, but the actual percentage for a specific place or situation can be very different, for wind turbines as well as other sources.

Some think that it is too early to define exposure-effect relations for wind turbines [20,35]. According to them, the influence of context (like residential factors, trust in

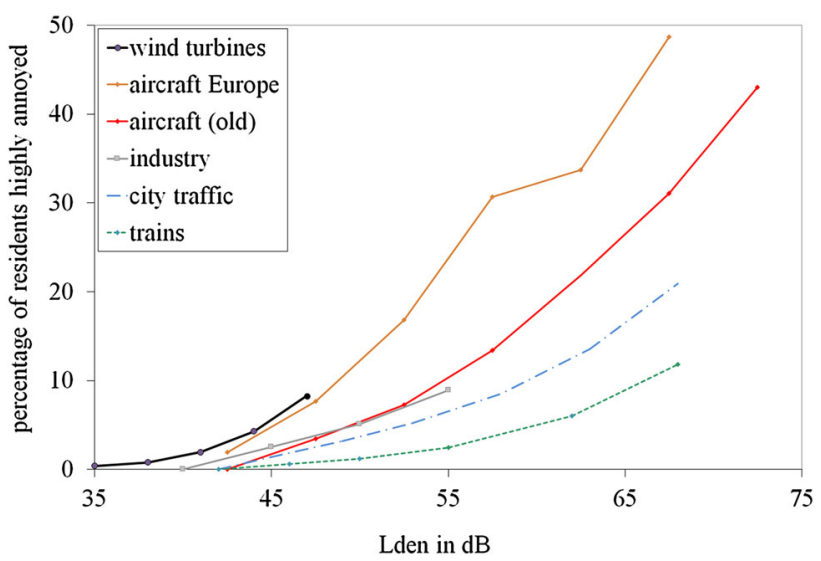

Fig. 2 Comparison of the percentage highly annoyed residents from sound of wind turbines, transportation and industry (approach adapted from Janssen et al. [51]); see text for explanation of legend 
authorities and the planning process, situational factors) and personal factors (such as noise sensitivity and attitude) is so strong that the exposure-effect relation can only (or at best) give an indication of the percentage of highly annoyed at the local level $[22,23]$.This is not unique to wind turbines, but is to some degree-also true for other sound sources and in part explains why in specific places or situations the actual percentage of annoyed persons can differ from the relations in Fig. 2. Michaud et al. [36] compared the results from five studies and found there was a $7.5 \mathrm{~dB}$ variation in wind turbine sound levels that led to the same percentage of annoyed persons.

\section{What makes wind turbine sound so annoying?}

In a Dutch survey [37] $75 \%$ of the respondents indicated that the terms 'swishing/lashing' gave the best description of wind turbine sound, irrespective of their being annoyed or not [37]. Laboratory studies have consistently shown that the periodic variation in the sound of wind turbines adds to the annoyance. In the study of Persson Waye and Öhrström [38] it was found that wind turbine sounds described as 'swishing', 'lapping' or 'whistling' were more annoying while the least annoying sounds were described as 'grinding' and 'low frequency' [38]. In the UK research was performed near three dwellings where people complained about wind turbine sound. Rather than the low-frequency component of the sound amplitude modulation or the rhythmic character was the most conspicuous aspect of the sound [39]. In a later UK study Large and Stigwood [40] concluded that amplitude modulation is an important aspect of the intrusiveness of wind turbine sound. More recently Yoon et al. [12] stated that there is a strong possibility that amplitude modulation is the main reason why wind turbine sound is easily detectable and relatively annoying.

Whether the type of environment affects the levels of annoyance is not yet clear. It can be assumed that people in rural areas are more likely to hear and see wind turbines than in more built-up urban areas with more buildings and a less open view. However, Dutch research showed that the percentage of highly annoyed people was equally high in rural and urban areas [37] although the correlation with the wind turbine sound level was less strong in the built-up area [41]. An important moderator was the existence of a busy road nearby, reducing the percentage annoyed by wind turbine sound annoyance in rural areas only. In a Swedish study it was found that residents in rural areas reported more annoyance in rural areas than in urban environments, possibly due to their expectation that the rural area would be quiet [42]. In a recent study Qu et al. [43] found that the level of annoyance from wind turbine sound in urban and suburban areas was less than reported in the Swedish, Dutch, Polish and Canadian studies in rural areas.

\subsubsection{Sleep Disturbance}

Good sleep is essential for physical and mental health. Sound is one of the factors that can disturb sleep or affect the quality of sleep. Several biological reactions to night time sound from different sources have been described in the literature: increased heart rate, waking up, difficulty in falling asleep and more body movements (motility) during sleep [4]. The night noise guidelines of the WHO are not specifically aimed at noise from wind turbines, but cover a range of (other) noise sources. It is conceivable that the relatively small but frequently occurring sound peaks just above the threshold for sleep disturbance due to the rhythmic character of wind turbine sound cause sleep disturbance [44]. A Dutch study found that wind turbine sound did not affect self-reported sleep onset latency but did negatively influence the ability to keep sleeping $[37,41]$. An increase in sound level above $45 \mathrm{dBA}$ increased the probability of awakening. This was not the case for people who obtained economic benefit from the wind turbines, but this might also have been an age effect (co-owners of the turbines were younger). These findings of the study in the Netherlands are in line with the conclusions which the WHO drew from the review of scientific literature the relation between transport sound and sleep [4]. According to the WHO, sleep disturbance can occur at an average sound level at the facade at night (Lnight) of $40 \mathrm{~dB}$ and higher [4].

A direct association between wind turbine sound and sleep disturbance can only be determined when there is a measurable reaction to the sound. Such an immediate influence is only plausible when the sound level is sufficiently high and as yet has not been convincingly shown for wind turbine sound $[23,45]$. An indirect effect has been shown between selfreported sleep disturbance and annoyance from wind turbine sound, but not between sleep disturbance and the sound levels per se [41]. Research has shown that also for other sound sources there is a high correlation between self-reported sleep disturbance and annoyance from noise [46].

Several more recent studies show an association between quality of life and sleep disturbance and the distance of a dwelling to a wind turbine $[47,48]$. Differences in perceived quality of life were associated with annoyance and self-reported sleep disturbance in residents. These results are highly comparable with those found for air and road traffic, e.g. see [49].

\subsubsection{Other Health Effects Due to Sound}

In an Australian report [50] the number of people living in the vicinity of wind turbines with serious health complaints was estimated to be $10-15 \%$. However, according to literature reviews on the health effects of wind turbines $[1,19,20,23$ $25,28]$ there is no evidence for health effects caused by wind turbines in people living in the vicinity of wind turbines, other 
than annoyance and self-reported sleep disturbance and the latter is inconclusive. There was, however, a clear correlation between annoyance and self-reported sleep disturbance in one study [41]. Based on existing field studies, there is insufficient evidence that living near a wind turbine is the direct cause of health effects such as mental health problems, headaches, pain, stiffness or diseases such as diabetes, cardiovascular disease, tinnitus and hearing damage.

\subsubsection{Influence of Situational and Personal Factors}

Research in the past decade has shed some light on the question why some people are more disturbed by wind turbines than others. Next to physical aspects, personal and contextual aspects influence the level of annoyance. Often these aspects are referred to as non-acoustic factors, complementary to the acoustic factors (the 'decibels'). Because the term non-acoustic refers to a broad range of aspects, and as a result is very unspecific, we prefer the term personal and contextual factors [51]. They can be subdivided in the following categories (with some exemplary aspects in brackets):

- Situational factors (visual aspects frequency of sound events, meteorological circumstances, other sound sources, distance to amenities and attractiveness of the area).

- Demographic and socio-economic factors (age, gender, income, level of education);

- Personal factors (fear or worry in relation to source, noise sensitivity, economic benefit from the source);

- Social factors (expectation, attitudes towards producers or government, media coverage);

There is a lot of variation in the aspects studied and also the strength of the evidence varies strongly. Without pretending to be exhaustive, those aspects documented in the reviews on wind turbine sound up to 2015 are discussed in more detail below.

\subsubsection{Visual Aspects}

Modern wind turbines are visible from a considerable distance because they rise high and change the landscape. Due to the movement of their rotor blades, wind turbines are more salient in the landscape than objects that do not move. The rotating blades draw our attention and can cause variations in light intensity when the blades block or reflect sunlight. The visual and auditory aspects have been shown to be highly interrelated $[19,36,52]$ and are therefore hard to unravel with respect to their effects. Annoyance from visual aspects may add to or even reinforce annoyance from noise (and vice versa). Noise and visual annoyance are strongly related as was also described above. It has been suggested [20] that people who see the wind turbines from their homes are more worried about the health effect of continuous exposure and as a consequence also report more annoyance [20].

\subsubsection{Economic Aspects}

Economic aspects can also affect annoyance from wind turbines. In a study of Pedersen et al. [52] in the Netherlands, some $14 \%$ of the respondents benefited from one or more wind turbines, in particular enterprising farmers who lived in general closer to the turbines and were exposed to higher sound levels than the remaining respondents. The percentage of annoyed persons in this group was low to very low, despite the higher exposure and the use of the same terms to describe the typical characteristics of wind turbine sound. In the study this group was described as 'healthy farmers': on average they were younger, more often male and had a higher level of education when compared to those not having economic benefits and reported less problems with health and sleep. However, it might not only be the benefit, but differences in attitude and perception as well as having more control over the placement of the turbines that might play a role [37].

\subsubsection{Noise Sensitivity}

Being noise sensitive refers to an internal state determined by physiological, psychological, attitudinal aspect, lifestyle and activities of a person that increases the reactivity to sound in general. Noise sensitivity has a strong genetic component (i.e. hereditary), but can also be a consequence of a disease (e.g. migraine) or trauma. Also, serious anxiety disorders can go together with an increased sensitivity to sound and possibly lead to a feeling of panic [53]. Only a few studies have addressed this issue in relation to wind turbine sound. An early example is the study of Shepherd et al. [47] in New Zealand, in which two groups were compared (a 'turbine group' versus a control group). Noise sensitivity was measured with a single question informing whether people considered themselves as noise sensitive. In the turbine group a strong association was found between noise sensitivity and annoyance and a weak association in the control group. This is indicative of an interaction effect of exposure and sensitivity on annoyance. This has also been documented for other sound sources [54]. According to a case report from Thorne [50], a relatively high proportion of residents near two wind farms in Australia were noise sensitive. Self-selection into a 'quiet area' by noise sensitive people can be a plausible explanation.

\subsubsection{Social Aspects}

For the social acceptance of wind turbine projects by a local community, the Belgian Superior Health Council [20] stated it is crucial how the community evaluates the consequences for their future quality of life. The communication and relation between the key parties (residents, municipality and project developer) are very important. Disturbance by wind 
turbines is a complex problem, in which the objective (physical) exposure and personal factors play a role, but also policy, psychology, communication and a feeling of justice.

When planning and participation are experienced as unjust or inadequate, public support will soon deteriorate, also among people who were originally neutral or in favour of the wind farm [55]. When residents feel they have been insufficiently heard, they feel powerless and experience a lack of control over their own environmental quality and quality of life. Worry or concern can be reduced by an open and honest procedure in which residents can contribute to the decisions in a positive way [56]. Already in the early phase of wind energy, research from Wolsink [57] and later from Breukers [58] showed that collaboration with emphasis on local topics was more successful than a policy aimed at as much wind energy as possible and a non-participatory approach.

Pedersen et al. [52] found that people who perceive the wind turbines as intruding and a threat to their privacy (motion, sound, visual) reported more annoyance. When people feel attached to their environment ('place attachment'), the wind farm can form a threat to that location and can create resistance [59]. Also, a feeling of helplessness and procedural injustice can develop when people feel they have no real say in the planning process. Potentially, this plays a role especially in rural areas where people choose to live because of tranquillity; for them the wind park can form an important threat (visual and auditory). Based on renewable energy projects in the UK, Walker and Devine-Wright [60] concluded that the more people participated in project development, the higher was the public support for renewable energy in general.

\subsection{Evidence Since 2015 Based on New Studies}

In the period between January 2015 and 2017, 22 relevant publications were identified in peer-reviewed literature. These are 10 on field studies [36,61-69], 7 on experiments [12,70-75], 3 on a prospective cohort study [76-78], 1 panel study [79] and 1 qualitative analysis of interviews and discourse [80]. After the systematic literature search, two relevant papers from the most recent International Wind Turbine Noise Conference (Rotterdam 2017) were included [43,81].

Two major studies were (partly) reported in this period and not included in the reviews, one in Canada [16,61-65] and one in Japan $[66,67]$. The study from Health Canada [36,61-65] was performed with 1238 adult residents living at varying distances from wind turbines. A-weighted sound levels outdoors were calculated as well as C-weighted levels, and additional measurements were made at a number of locations. A strong point of the study is the high response rate of $79 \%$. The results were presented in six publications, addressing effects on sleep, stress, quality of life, noise annoyance and health effects and a separate paper on the effect of shadow flicker on annoyance. Also, two papers were published describing the assessment of sound levels near wind turbines and near receivers [82,83]. The Japanese study by Kakeyama et al. $[66,67]$ pertains a field study with structured face-to-face interviews at 34 study sites and 16 control sites. Wind turbine sound levels were estimated based on previous measurements at some sites and expressed in LAeq. Outcomes studied were sleep deprivation, sleep disturbance and physical and mental health symptoms (Table 3 ).

The next sections describe the state of the art in more detail per health effect as in 3.1. Note again that the description is limited to the effects of wind turbine sound in the 'normal' frequency range. Findings from studies addressing suggested specific impacts of the low-frequency component and infrasound distinct from 'normal' sound are summarized separately in Sect. 4.

\subsubsection{Noise Annoyance}

In one of his papers about the Health Canada study, Michaud et al. [61] describe the findings on annoyance, self-reported health and medication use. In line with earlier findings the study confirms that the percentage of highly annoyed increased significantly with increasing wind turbine sound levels. The effect was highest for annoyance with visual aspects of wind turbines, followed by blinking lights, shadow flicker, sound and vibrations.

An Iranian study of Abasssi et al. [68] included 53 workers divided in three job groups with repairing, security and administration tasks. The exposure level to wind turbine sound of employees at each job group was measured as an 8-h equivalent sound level as is usual in working conditions. Outcome measures included annoyance, sleep, psychological distress and health complaints. Noise sensitivity, age, job stress and shift work were accounted for. Annoyance was associated with measured sound levels but lower than found in residential studies. The other health outcomes did not show a significant association. It is not clear how this relates to residential conditions as the situations are quite different and different factors are involved.

In the period 2015-2017 several laboratory studies have addressed the effects of wind turbine sound and annoyance. In a listening test among 60 people, after a pilot in 12 people, an association was found by Schäffer et al. [70] between road traffic and wind turbine sound level or variations in sound level due to amplitude modulation and annoyance. Attitude towards wind turbines and noise sensitivity were important confounders, and the frequency of the amplitude modulation (higher for the wind turbine sound) seemed to play an important role.

The relative contribution of the typical characteristics of wind turbine sound, and particularly the rhythmic character or amplitude modulation (AM) was studied in several exper- 


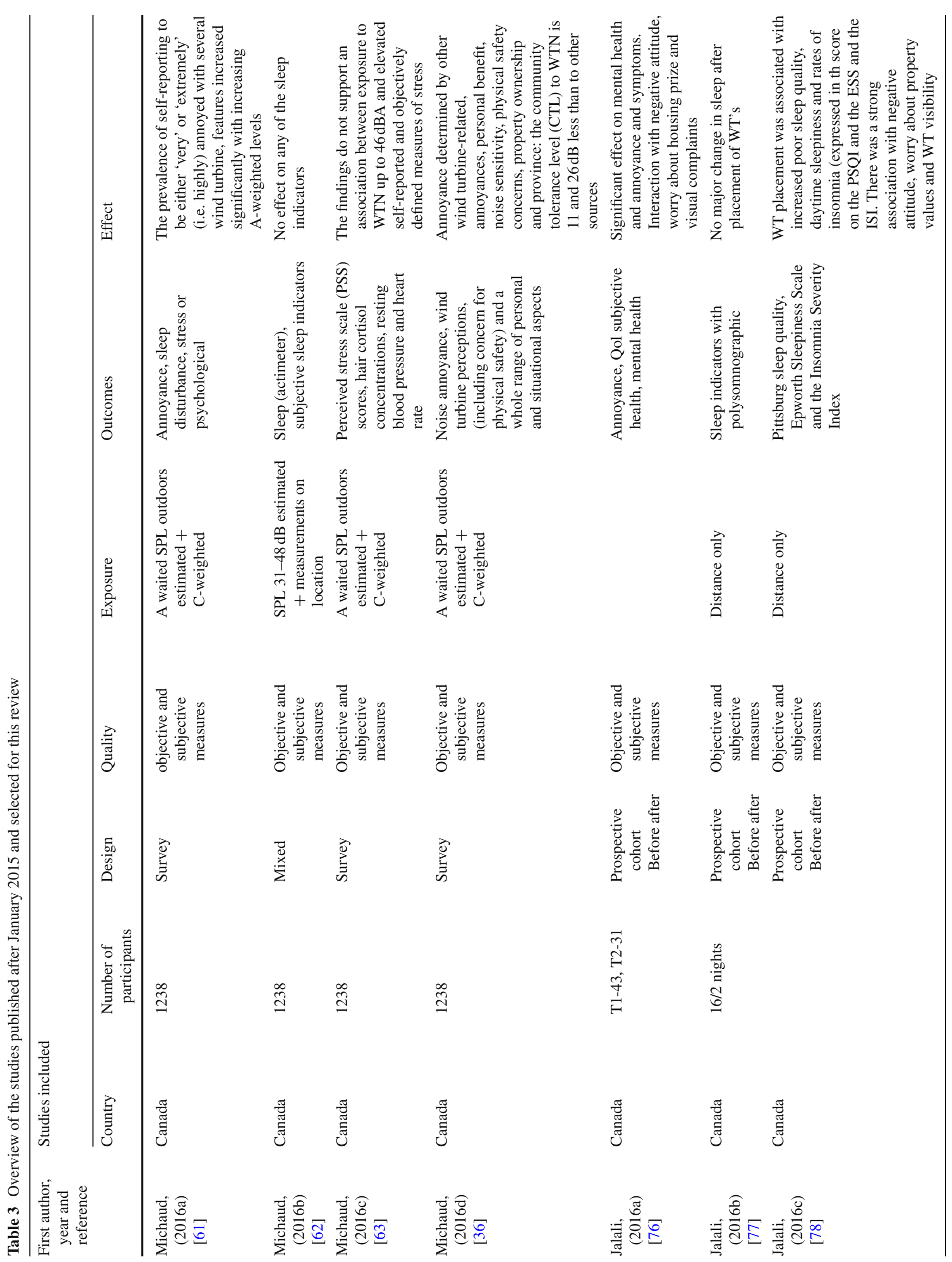




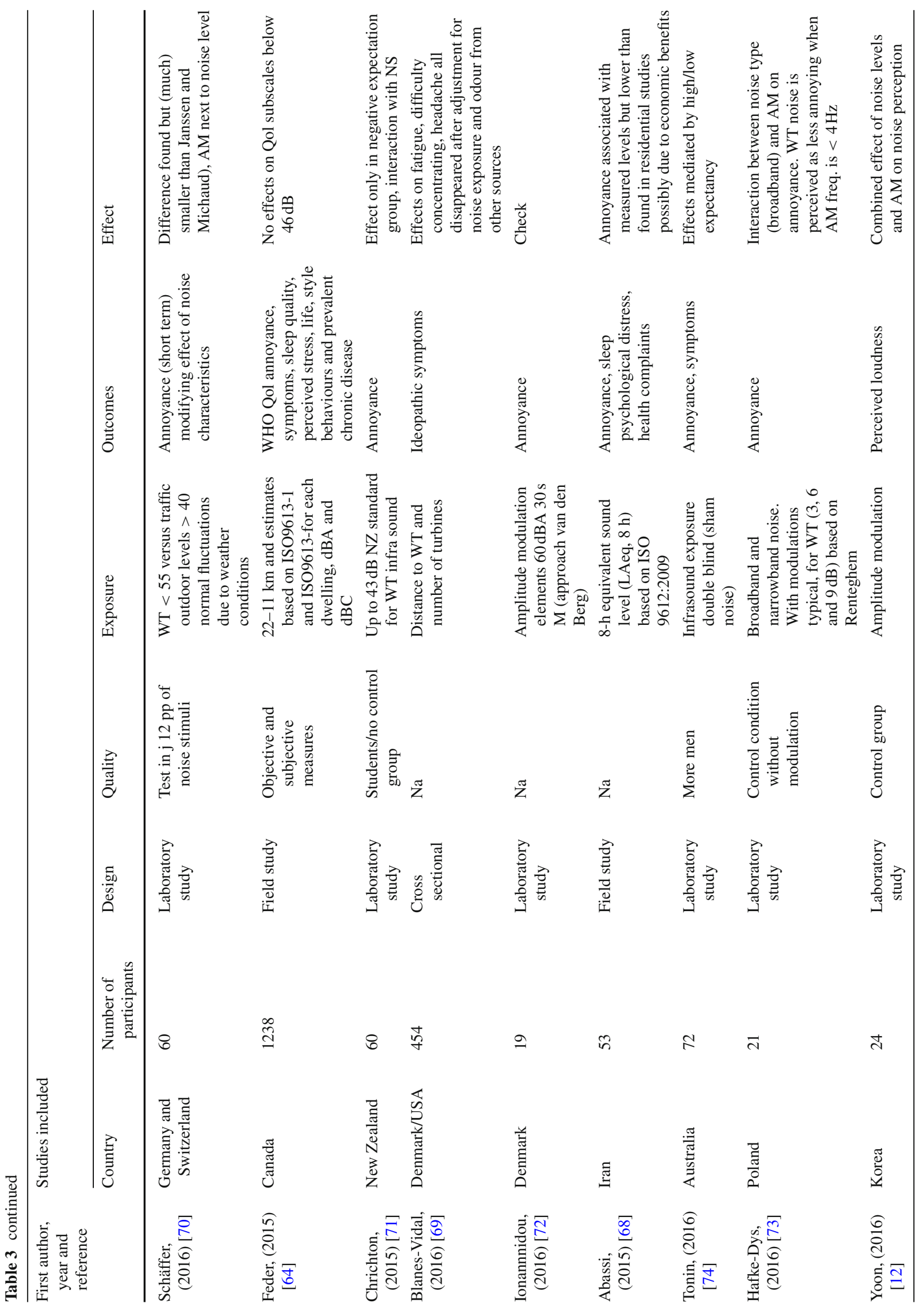




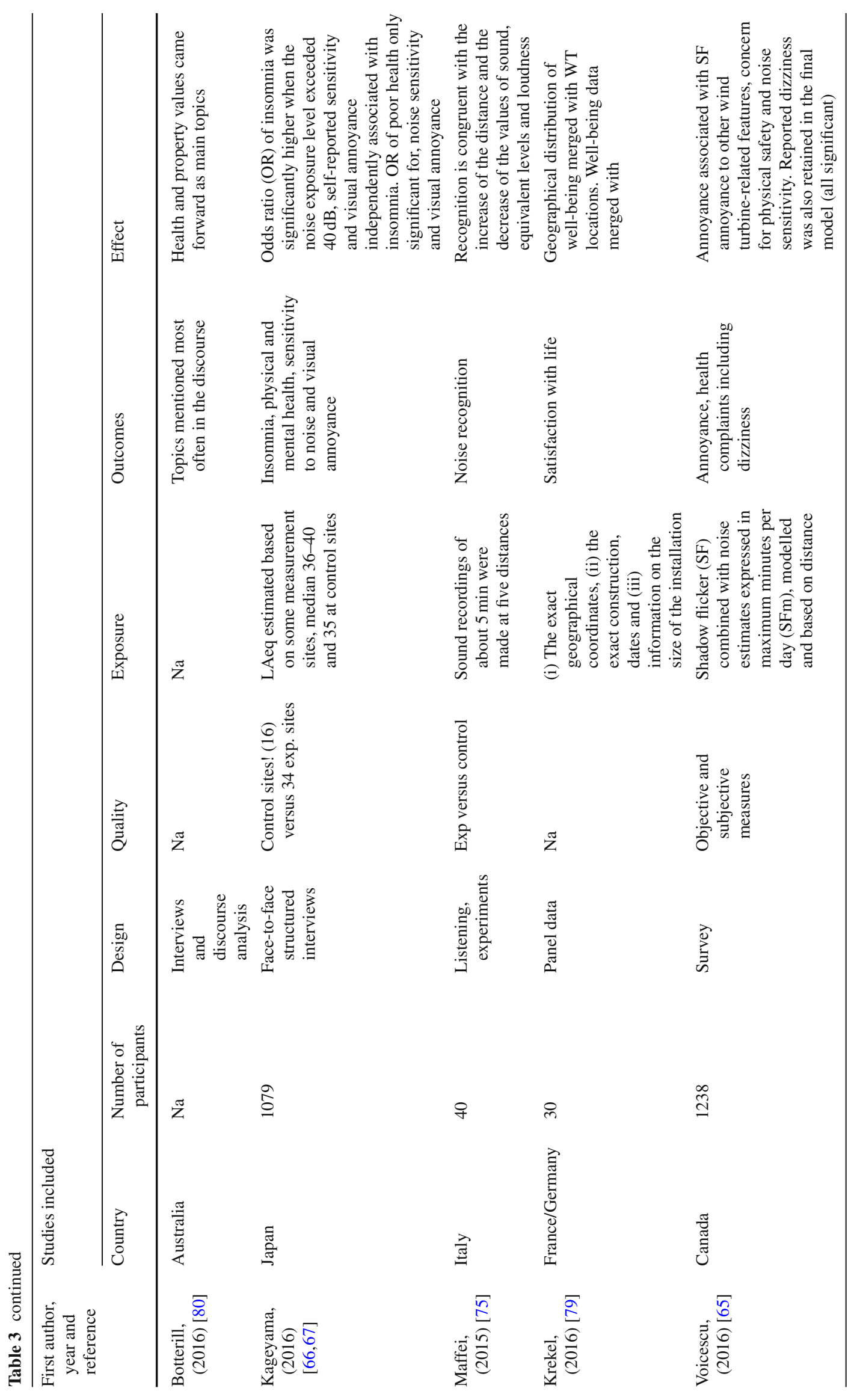




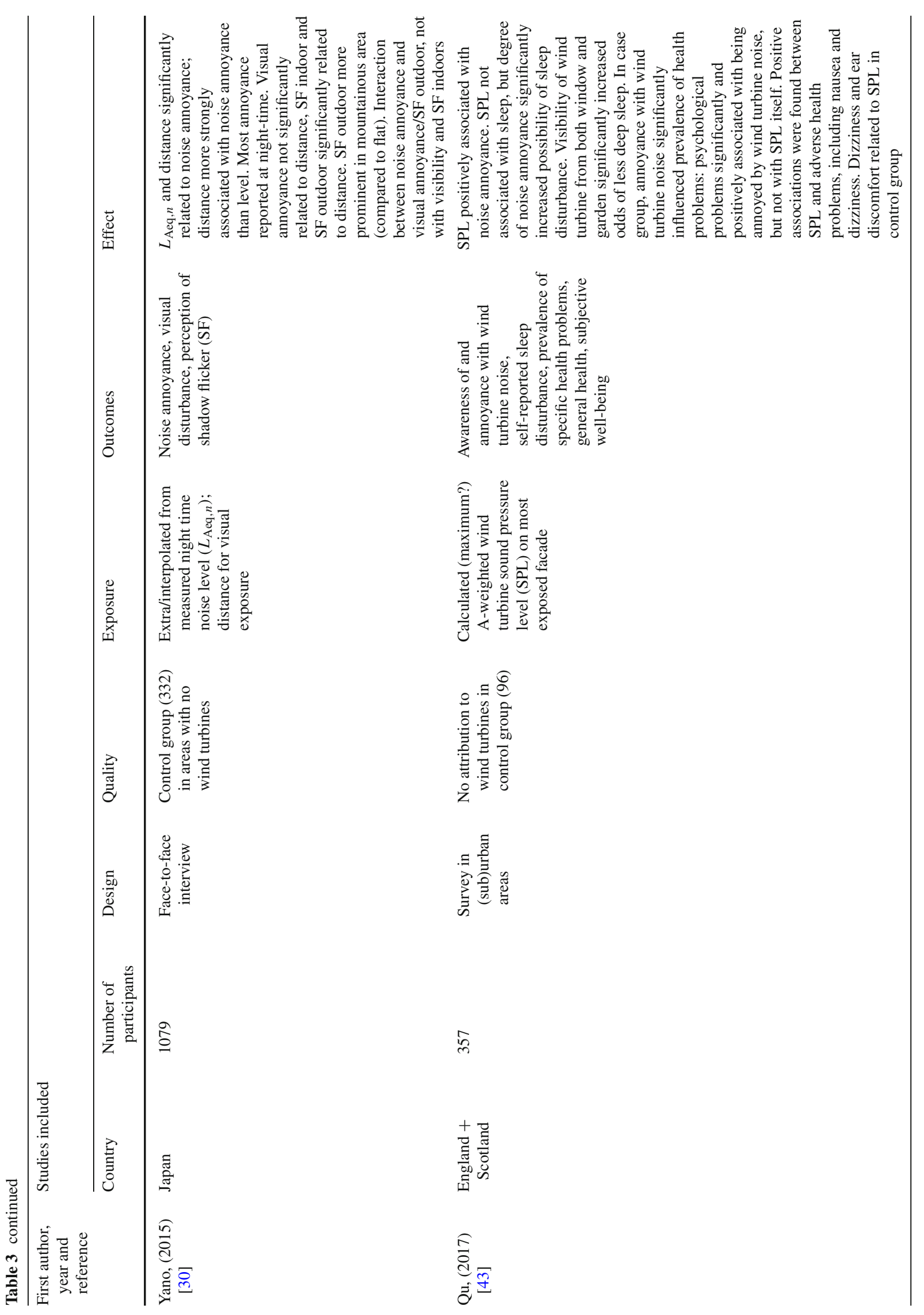


iments. Ionannidou et al. [72] report on a study among 19 volunteers in which the effect of changes over time in the amplitude modulation of wind turbine sound on annoyance was investigated. The changes could either be the frequency of the modulation, the depth (or strength) of the modulation or a change in depth over time. The study confirms earlier results that AM leads to a higher annoyance rating. A higher modulation frequency (from 0.5 to $2 \mathrm{~Hz}$ ) also resulted in a higher rating, but the effect was not significant. There was also a higher annoyance rating when the modulation depth increased intermittently, but again this was not significant. Because of the limited statistical power of these tests (because of the low number of participants and the limited time), it was recommended to investigate the variations in AM for a longer period and in a field setting.

A study from Hafke-Dys et al. [73] among 21 volunteers again concerned the effect of amplitude modulation on annoyance. In this study sounds with several modulation conditions were compared to a non-modulation condition. The test sounds used were (1) sound from moving cars, passing at a rate of 1-4 per second; (2) broadband sound with the same spectrum as wind turbines and (3) narrowband sound that could be modulated at 1,2 and $4 \mathrm{~Hz}$. All three types of sound had modulation depths typical for wind turbines at 3, 6 and $9 \mathrm{~dB}$ similar to Van Renterghem et al. [84], or zero (no modulation). Results showed that AM did increase annoyance in the case of broadband sound and passing cars, but not for the narrow band sound. The modulated sound was more annoying with increasing modulation frequency, in agreement with an expected highest sensitivity for modulated sounds at $4 \mathrm{~Hz}$. Large, modern wind turbines modulate their sound at a frequency close to $1 \mathrm{~Hz}$. The effect of AM on annoyance was less for the broadband sound than for passing cars. The main difference between these two sounds was the spectral content, with the broadband sound having more lowfrequency sound than the passing cars. The authors conclude that this result supports the Japanese study [13] in which it was demonstrated 'that low frequency components are not the most significant problem when it comes to the annoyance perception of wind turbine noise'.

Yoon et al. [12] studied the reaction to modulation of wind turbine sound in 12 people. Findings show again that there is an association between AM and level of annoyance. The authors conclude that there is a strong possibility that amplitude modulation is the main cause of two typical properties of wind turbine sound: that it is easily detectable and highly annoying at relatively lower sound levels than other noise sources. They add that this does not mean that these properties can be fully explained by the amplitude modulation.

Crichton and Petrie [71] studied 60 volunteers at exposure levels up to $43 \mathrm{dBA}$ (the New Zealand standard limit) in combination with infrasound $(9 \mathrm{~Hz}, 50 \mathrm{~dB})$. In one group, the participants were shown a video about the health risk of wind turbine infrasound, and in the second group a video on health benefits was shown. An effect on annoyance was found only in the group expecting to be negatively affected, and in this group noise sensitivity increased the likelihood of being annoyed. In the group expecting a positive effect, there was far less annoyance and almost no influence from noise sensitivity.

In a later publication from the Japanese study, it was found that within $860 \mathrm{~m}$ from a wind farm $10 \%$ of the residents were annoyed by shadow flicker while within $780 \mathrm{~m} 10 \%$ of the residents were highly annoyed by wind turbine sound [81]. The authors concluded that a minimum distance (or 'setback') between residences and wind farms should be considered from an aural and visual point of view.

\subsubsection{Sleep Disturbance}

Michaud et al. [62] reported on sleep disturbance from a field study involving 742 of the 1238 respondents (as described under 3.2) wearing an actimeter, to measure relevant sleep indicators during 3-7 consecutive nights after the interviews. Outdoor wind turbine sound levels were calculated following international standards. Neither self-reported sleep quality, diagnosed sleep disorders nor objective measures such as sleep onset latency, awakenings and sleep efficiency showed an immediate association with exposure levels up to $46 \mathrm{~dB}$ after adjustment for relevant confounders such as age, caffeine use, body mass index (BMI) and health condition. This partly contrasts with earlier findings on subjective sleep measures [47]. No study addressed objective sleep measures in relation to wind turbines before. However, it should be mentioned that the method of actigraphy is limited as compared to more elaborate polysomnographic measures as were employed by Jalali et al. [76] and described below. In the Health Canada study having to close the window in order to guarantee an undisturbed sleep had by far the strongest influence on annoyance [61]. This could be a reason that no relation between wind turbine sound level and sleep disturbance was found: if persons disturbed at night by wind turbine sound would close their bedroom window, the result could be that they are less disturbed at night by the sound as such, although they could be annoyed because they had to close the window. The results do not directly support or negate this explanation. However, those closing their bedroom windows was eight times more likely to be annoyed. At higher wind turbine sound levels, people more often gave wind turbines as a reason for closing the bedroom window [61].

Kakeyama et al. [66,67] showed a significant association between sound levels above $40 \mathrm{~dB}$ and sleeping problems (insomnia). These findings are in contrast with those reported by Michaud et al. [62] who did not observe an immediate association between sound exposure levels up to $46 \mathrm{dBA}$ 
and subjective and objective indicators for sleep. The earlier findings of Bakker [41] regarding subjective sleep indicators showed that sleep disturbance seemed to be related to sound level only when no others factors were included. When annoyance with wind turbine sound was included, then sleep disturbance was related to that annoyance and not anymore to sound level. Earlier, Pedersen and Persson [42] also concluded on an association between annoyance and sleep disturbance rather than a direct effect of sound level.

Jalali et al. [77] measured sleep disturbance in a group of 16 people for 2 consecutive nights using a polysomnographic method including a range of sleep and physiological parameters such as sleep onset, duration, movement during sleep, awakening, EEG activity. Sound measurements over the whole frequency range $(0.5-20,000 \mathrm{~Hz})$ were performed in the bedroom as well as outdoor, while accounting for weather conditions, wind speed and temperature. Factors that were taken into account were attitude, sensitivity, visibility, distance within $1000 \mathrm{~m}$ and windows open versus closed. Results showed no major changes in the sleep of participants who had new wind turbines in their community. There were no significant changes in the average indoor ( $31 \mathrm{dBA})$ and outdoor sound levels (40-45 dBA before, 38-42 dBA after) before and after the wind turbines became operational. None of the participants reported waking up to close their windows because of the outside noise. The lack of an effect might be explained by the limited measurements (two nights) or the low indoor sound levels that almost equalled the threshold value for sleep disturbance of $30 \mathrm{dBA}$.

In another paper Jalali et al. [78] report on the association between measured wind turbine sound levels and subjective sleep quality as measured with the Pittsburgh sleep quality index. Results show only an indirect association with attitude towards the wind turbines and concern about reduced housing values and the visibility of the turbine from the properties. The results confirm the strong psychological component and individual differences in sleep disturbance from wind turbine sound.

\subsubsection{Other Health Effects Due to Sound}

From the Canadian study Michaud et al. [61] concluded that, except for annoyance, the results do not support an association between exposure to wind turbine sound up to $46 \mathrm{dBA}$ and the evaluated health-related end points, such as mental health problems, headaches, pain, stiffness, or diseases such as diabetes, cardiovascular disease, tinnitus and hearing damage. Michaud et al. [63] also studied the association between wind turbine sound level and objective stress indicators (cortisol, heart rate) and perceived stress (PPS index). These stress indicators were weakly associated with each other, but analysis showed no significant association between exposure to wind turbine sound (up to $46 \mathrm{dBA}$ ) and self-reported or objective measures of stress. The authors remarked that there was also no association between stress indicators and noise annoyance, which does not support the hypothesis that stress can be a consequence of chronic annoyance. The only wind turbine-related variable that had an influence on stress was high annoyance with the blinking lights on top of the wind turbines [63]. McCunney et al. [25] found an explanation for a lack of significant associations in the fact that sound levels from wind turbines do not reach levels which could cause such direct effects.

Results for quality of life (Qol) [64], measured using the WHO Qol index and including physical, environmental, social quality and satisfaction with health, showed no relation with sound levels (at levels up to $46 \mathrm{~dB}$ ). This is in contrast with findings reported earlier by Shepherd et al. [47] and Nissenbaum et al. [48]. However, the results of these studies are hard to compare because the exposure levels are not the same and because different instruments were used to measure perceived quality of life

Tonin et al. [74] studied 72 volunteers in a laboratory setting for a double-blind test similar to that of Crichton et al. [71] but used infrasound at a higher level (91 dB). Before the listening test, participants were influenced to a high expectancy of negative effects from infrasound with a video of a wind farm affected couple, or a low expectancy of negative effects with a video of an academic explaining why infrasound is not a problem. Then normal wind turbine sound was presented via a headset to all participants with the inclusion of the infrasound or no infrasound for a period of $23 \mathrm{~min}$. The infrasound had no statistically significant effect on the symptoms reported by participants, but the concern they had about the effect of infrasound had a statistically significant influence on the symptoms reported.

A survey in Denmark [69] among 454 citizens living in rural areas at different distances to wind turbine farms with a varying numbers of wind turbines studied the effect on nonspecific symptoms. The study included idiopathic symptoms (i.e. not related to a specific disease) as effects and distance to the wind farm and the number of turbines as a measure of exposure. The originally positive association of distance with fatigue, headaches and concentration problems all disappeared after adjustment for exposure to sound and odour from other sources.

Jalali et al. [76] report on a prospective cohort (i.e. before-after) study with 43 participants who completed a questionnaire in spring 2014 and again a year later. Exposure to a wind farm was only measured in terms of distance. Residents who were annoyed by the sound or sight of turbines, or who had a negative attitude towards them or were concerned about property devaluation, after 1 year experienced lower mental health and life quality and reported more symptoms than residents who were not annoyed and had positive attitudes towards turbines. The response rate for this study was 
low (only 22\%), and 12 people (of 43 that is approximately $25 \%$ ) were not in the second round. Another weak point is the lack of a control group.

Against the background of the increasing number of wind farms in Germany, Krekel et al. [79] investigated the effect of the presence of wind turbines on residential well-being by combining household data from the German SocioEconomic Panel with a dataset on more than 20,000 wind turbines for the time period between 2000 and 2012. The key effect studied was life satisfaction. Results showed that the construction of one or more wind turbines in the neighbourhood of households had a significant negative effect on life satisfaction. This effect was limited in both distance and time.

More recent the first results were published of a new British study that was held near wind turbines in densely populated, suburban areas [43]. In this study part of the participants received a questionnaire that included explicit questions on the impacts of the local wind turbines on wellbeing, and the remaining part received a variant with no such questions. When including all participants, there was less annoyance from wind turbine sound in this study compared to what was found in earlier (Swedish, Dutch, Polish and Canadian) studies in rural areas. For the first group (with questions concerning local wind turbines), the sound levels were not significantly related to health problems and this group reported less health problems and better general health; this was opposite to the relationship found in the other, variant group.

\subsubsection{Influence of Situational and Personal Factors}

\subsubsection{Visual Aspects}

The paper of Voicescu et al. [65] on the Canadian data set (see Sect. 3.2) studied the effect of shadow flicker, expressed as the maximum duration in minutes per day, in combination with sound levels and distance, on annoyance and health complaints including dizziness. As shadow flicker exposure increased, the percentage of highly annoyed increased from $4 \%$ at short duration of shadow flicker $(<10 \mathrm{~min})$ to $21 \%$ at $30 \mathrm{~min}$ of shadow flicker. Variables associated with the percentage highly annoyed due to shadow flicker included concern for physical safety and noise sensitivity. Reported dizziness was also found to be significantly associated with shadow flicker.

\subsubsection{Economic Aspects}

In the study of Michaud et al. [16] personal (economic) benefit was associated with less annoyance, in a significant but modest way, when excluding factors that were likely to be a reaction (such as annoyance) to the wind turbine operation. The association between personal benefit from a wind turbine was also found in the Netherlands [85]. In the Japanese study from Kageyama et al. [66,67], this relationship was not found to be significant. However, it might not only be the benefit, but differences in attitude and perception as well as having more control over the placement of the turbines that might play a role [37].

\subsubsection{Noise Sensitivity}

Recent studies of Michaud et al. [36] and Kageyama et al. [66,67], both from 2016, confirm the independent role noise sensitivity has on reaction to wind turbines (see also Sect. 3.1.4.3). The influence of noise sensitivity on noise annoyance was reported earlier by many other researchers [42,59,86-88]. In all these studies, being highly noise sensitive was related to more annoyance. Similarly, the odds of reporting poor QoL and dissatisfaction with health were higher among those who were highly noise sensitive. However, after adjustment for current health status and work situation (unemployment) the influence of noise sensitivity became marginal. Fear and concern about the potential harm of wind turbines was an important predictor of annoyance as has been reported earlier for other noise sources [89-92].

In the Canadian study length of exposure seemed to be an important situational factor and led to up to 4 times higher levels of annoyance for people living more than 1 year in the vicinity of a wind turbine. This indicates sensitization to the sound rather than adaptation or habituation as is often assumed. The moderate effect of wind turbine sound level on annoyance and the range of (other) factors that predict the level of annoyance imply that efforts aimed at mitigating the community response to WTN will profit from considering other factors associated with annoyance. In the Japanese study $[66,67]$ poor subjective health was not related to wind turbine sound levels, but again noise sensitivity and visual annoyance were significant predictors for the effects studied. Both noise sensitivity and visual annoyance seem, according to them, to be indicators of a certain vulnerability to environmental stimuli or changes in environmental factors.

Maffei et al. [75] studied 40 people subdivided in an experimental and control group (familiar for a long time with wind turbine sound versus not familiar). The study included a listening test to sound recorded at a wind farm of 34 wind turbines including background sound (wind in vegetation), or only background sound. Sound recordings of about 5-min duration were made at five distances $(150,200,250,300$ and $1500 \mathrm{~m}$ ) from the wind farm. For each distance 65 soundtracks were used. The aim was to detect wind turbine sound at varying distances. For both groups of participants, familiar and unfamiliar, there was no difference in recognition of wind turbine sound at distances of $300 \mathrm{~m}$ or less and detection was easiest at distances up to $250 \mathrm{~m}$. At $1500 \mathrm{~m}$ those familiar with wind turbine sound could detect the sound better, but they also reported more often 'false alarms'. Noise sensitivity was an important factor. 


\subsubsection{Social Aspects}

According to Chapman et al. [93] and Crichton et al. [94], there is a strong psychogenic component in the relation between wind turbine sound and health complaints. This is not unique for wind turbine sound but has been documented for other sources as well, see e.g. [89,95,96]. In both studies $[93,94]$ attention was given to expectations on the level of annoyance and the level of awareness ('notice') of the characteristics and prominent sounds of wind turbines [84]. The influence of these factors has been found in many studies regarding the effects of other sound sources [97]. In more recent years many researchers have investigated the social acceptance of wind projects in a number of countries by local communities and many stress the relevance of a fair planning process and local involvement [98-101]. The influence of injustice and fair planning process are confirmed in the most recent studies. Jalali [76] e.g. showed that concern about decreases in property values was associated with mental health problems.

Finally, Botterill and Cockfield [80] studied the discourse about wind turbines in submissions to public inquiries and in a small number of detailed interviews, and topics addressed in the discourse. Health and property values were found to be the most prominent topics discussed in the inquiries with regard to wind turbines in the submissions (and aesthetics/landscape arguments less often), but in the interviews these were never mentioned.

\section{Health Effects of Low-Frequency Sound and Infrasound}

In the non-scientific literature, which can be found on the internet, a range of health effects is attributed to the presence of wind turbines. Infrasound is described as an important cause of these effects, also when the infrasound levels must be very low or are unknown. In this section the question is whether infrasound or low-frequency sound deserves special consideration with respect to the effects of wind turbine sound. There is some discrepancy when comparing conclusions from the majority of scientific publications to conclusions in popular publications. Also, some scientific publications suggest possible impacts that are not generally supported. The findings regarding low-frequency sound and infrasound are not easy to interpret. It may be confusing that the frequency of the rhythmic changes in sound due to amplitude modulation is the same as the frequency of an infrasound component. Also, some authors conclude that low-frequency sound and infrasound play a role in the reactions to wind turbine sound that is different from the effects of 'normal' sound $[16,102]$ which is contested by many others. In general, however, there is little definite evidence on specific health effects of low-frequency sound when compared to health effects from 'normal' sound [103].

First, we will consider the audibility of infrasound and low-frequency sound and then possible health effects not involving audibility. Because we are, in the case of lowfrequency sound and infrasound, dealing with other health effects, the paragraphs are structured different than was the case in the previous section.

\subsection{Audibility of Infrasound and Low-Frequency Sound}

Audible low-frequency sound is all around us, e.g. in road and air traffic. Audible infrasound is less ubiquitous, but can be heard from big machines and storms. In most publications on wind turbine sound, there is agreement that infrasound and low-frequency sound are both present in wind turbine sound. Generally, it is acknowledged that wind turbine infrasound is inaudible as infrasound levels are low with respect to human sensitivity [16, 19,25,104,105].

Even close to a wind turbine, most authors argue that infrasound is not a problem with modern wind turbines. This can be shown from measurement results at 10 and $20 \mathrm{~Hz}$. At the (infrasound) frequency of $10 \mathrm{~Hz}$ the A-weighted sound power level is typically $60 \mathrm{~dB}$ lower than the total sound level in $\mathrm{dBA}$ [15]. At a receiver with a total sound level of $45 \mathrm{dBA}$ this means that the $10 \mathrm{~Hz}$ sound level is about minus $15 \mathrm{dBA}$ or, in physical terms (not A-weighted), $55 \mathrm{~dB}$. This is far below the hearing threshold at that frequency, which for normal-hearing persons is about $95 \mathrm{~dB}$. A sound of $55 \mathrm{~dB}$ at $10 \mathrm{~Hz}$ would also be inaudible for the few persons that have been reported with a much lower hearing threshold (close to $80 \mathrm{~dB}$ ). At $20 \mathrm{~Hz}$, the upper frequency limit of infrasound, the result, again at a receiver total sound level of $45 \mathrm{dBA}$, would be a physical level of wind turbine sound of $50-55 \mathrm{~dB}$ which is much lower than the normal hearing threshold at that frequency of $80 \mathrm{~dB}$ [106].

As a part of a Japanese study on wind turbine lowfrequency sound, persons in a laboratory were subjected to wind turbine sound where very low frequencies were filtered out over different frequency ranges [13]. When infrasound frequencies were filtered out, the study persons did not note different sensations. Above about $30 \mathrm{~Hz}$ they began to notice a difference between the filtered and original sound.

Leventhall [107] states that the human body produces infrasound internally (through blood flow, heartbeat and breathing, etc.) and this would mask infrasound from outside sources when this sound is below the hearing threshold.

In contrast to infrasound, there is general agreement that low-frequency sound is part of the audible sound of wind turbines and therefore contributes to the effects caused by wind turbine sound. The loudest part of the sound as radiated by a turbine is in the mid-frequency range $(250-1600 \mathrm{~Hz})[15,16]$. This shifts to lower frequencies when the sound travels 
through the atmosphere and enters a building because absorption by the atmosphere and a building facade reduces low frequencies less than higher frequencies. However, studying the effects of the low frequencies separately from the higher frequencies is not easy as both frequency ranges automatically go together: wind turbines all have very much the same sound composition. In a Canadian study on wind turbines, the sound levels at the facades of dwellings were calculated as both A- and C-weighted sound levels, but this proved not to be an advantage as the two were so closely linked that there was no added value in using both [82]. A limit in Aweighted decibels (where the A-weighting mimics human hearing at moderate sound levels) thus automatically limits the low-frequency part of the sound [105].

Bolin et al. [108] calculated and compared wind turbine and road traffic sound over a broad frequency range (0$2000 \mathrm{~Hz}$ ) at sound levels considered acceptable in planning guidelines $\left(40 \mathrm{~dB} L_{\mathrm{Aeq}}\right.$ for wind turbine sound and $55 \mathrm{~dB}$ $L_{\text {Aeq }}$ for road traffic sound). Compared to road traffic sound, wind turbine sound had lower levels at low frequencies. Thus, at levels often found in urban residential areas, low-frequency sound from wind turbines is less loud than from road traffic sound. Recent measurements in dwellings and residential areas show that similar levels of infrasound occur, when comparing wind turbine sound with sound from traffic or household appliances [109].

\subsection{Effect of Lower Frequencies}

McCunney et al. [25] mention that both infrasound and lowfrequency sound have been suggested to pose possibly unique health hazards associated with wind turbine operations. From their review of the literature, including results from field measurements of wind turbine-related sound and experimental studies in which people have been purposely exposed to infrasound, they conclude that there is no scientific evidence to support the hypothesis that wind turbine infrasound and low-frequency sound has effects that other sources of infra/low-frequency sound do not have.

\subsection{Subaudible Effects}

Several authors have linked infrasound and low-frequency sound from wind turbines to health effects experienced by residents, assuming that infrasound can have physiological effects at levels below the (normal) hearing threshold [110 112]. This was supported by Salt and Kaltenbach [113] who argued that normal hearing is the result of inner hair cells in the inner ear producing electric signals to the brain in response to sound received by the ear. However, infrasound and low-frequency sound (up to $100 \mathrm{~Hz}$ ) can also lead to signals from the outer hair cells $(\mathrm{OHC})$ and the threshold for this is lower than for the inner hair cells. This means that inaudible levels of infrasound and low-frequency sound can still evoke a response [113]. The OHC threshold is $60 \mathrm{~dB}$ at $10 \mathrm{~Hz}$ and $48 \mathrm{~dB}$ at $20 \mathrm{~Hz}$. Comparing this to actual sound levels (see Sect. 4.1) shows that infrasound levels from wind turbines could just exceed this OHC threshold when their total outdoor sound level is $45 \mathrm{dBA}$. It is unlikely that the OHC threshold can be exceeded indoors, where levels are lower, except at a high sound level that may occur very close to a wind turbine. Salt and Kaltenbach [113] conclude from this that it is 'scientifically possible' that infrasound from wind turbines thus could affect people living nearby. However, it is not clear to what reactions these signals would lead or if they could be detrimental when just exceeding the $\mathrm{OHC}$ threshold. If such inaudible sound could have effects, it is not clear why this has never been observed with everyday sources (other than wind turbines) that produce infrasound and low-frequency sound such as strong winds, road and air traffic, or with physiological sounds from heartbeat, blood flow, etc.

Farboud et al. [114] conclude that physiological effects from infrasound and low-frequency sound need to be better understood; it is impossible to state conclusively that exposure to wind turbine sound does not cause the symptoms described by authors such as Salt and Hullar or Pierpont.

Leventhall [107] argues that infrasound at low level is not known to have an effect. Normal pressure variations inside the body (from heart beat and breathing) cause infrasound levels in the inner ear that are greater than the levels from wind turbines. From exposure to high levels of infrasound, such as in rocket launches and associated laboratory studies or from natural infrasound sources, there is no evidence that infrasound at levels of $120-130 \mathrm{~dB}$ causes physical damage to humans, although the exposure may be unpleasant [107].

Stead et al. [115] come to a similar conclusion when considering the regular pressure changes at the ear when a person is walking at a steady pace. The up and down movement of the head implies a slight change in atmospheric pressure that corresponds to pressure 'sound' levels in the order of $75 \mathrm{~dB}$. The pressure changes in the rhythm of the walking frequency are similar in frequency (close to $1 \mathrm{~Hz}$ ), and level to the pressure changes from infrasound at rotation frequencies measured at houses near wind farms.

\subsection{Vestibular Effects}

According to Pierpont the (infra)sound of wind turbines can cause visceral vibratory vestibular disease (VVVD), affecting the vestibular system from which we derive our sense of balance. She characterized this new disease with the following symptoms: 'a feeling of internal pulsation, quivering or jitteriness, and it is accompanied by nervousness, anxiety, fear, a compulsion to flee or check the environment for safety, nausea, chest tightness, and tachycardia' [111], stat- 
ing that infrasound and low-frequency sound were causing this 'wind turbine syndrome'. Pierpont's research was based on complaints from 38 people from 10 families who lived within $300-1500 \mathrm{~m}$ from one or more turbines in the USA or Great Britain, Italy, Ireland and Canada. In several publications (e.g. $[22,25]$ ), it was pointed out that Pierpont's selection procedure was to find people who suffer the most, and it was not made clear that it was indeed the presence of the wind turbine(s) that caused these symptoms. Although the complaints may be genuine, it is possible that very sensitive people were selected and/or media coverage had led to physical symptoms attributed to environmental exposures as has been demonstrated for wind turbines [93] and other environmental exposures [116]. Van den Berg [44] noted that the symptoms of VVVD are mentioned in the Diagnostic and Statistical Manual of Mental Disorders (DSM) as stress symptoms in three disorders: an adjustment disorder, a panic disorder and a generalized anxiety disorder. The wind turbine syndrome may thus not be a new phenomenon, but an expression of stress that people have and which could have a relation to their concern or annoyance with respect to a (planned) wind farm.

In his examination of the wind turbine syndrome, Harrison [27] argued that at a level of 40-50 dBA no component of wind turbine sound approaches levels high enough to activate the vestibular system. The threshold for this is about $110 \mathrm{~dB}$ for people without hearing ailments. In people with a hearing ailment, particularly the 'superior (semicircular) canal dehiscence syndrome' (SCDS), this threshold is lower and can be $85 \mathrm{~dB}$. Such levels are only reported very close to wind turbines. Reports show that $1-5 \%$ of the adult population may have (possibly undiagnosed) SCDS.

Schomer et al. [117] studied residents of three homes where residents generally did not hear the wind turbines in their area, but they did report symptoms comparable to motion sickness. Schomer et al. suggest that this could result from sound affecting the vestibular sensory cells and in their opinion wind turbine infrasound could generate a pressure that they compare with an acceleration exceeding the U.S. Navy's criteria for motion sickness. This has been investigated by Nussbaum and Reinis much earlier [118]. They exposed 60 subjects to a tone of $8 \mathrm{~Hz}$ and $130 \mathrm{~dB}$ with high distortion (high-level harmonics at multiples of $8 \mathrm{~Hz}$ ) or low distortion (harmonics at lower level). Dizziness and nausea were primarily associated with the low distortion exposure, i.e. a relatively high infrasound content. In contrast, headache and fatigue were primarily associated with the high distortion exposure, with a relatively low infrasound content. Nussbaum and Reinis [118] hypothesized that the effects of the purer infrasound could be explained as acoustically induced motion sickness. However, this was concluded from exposure levels $(130 \mathrm{~dB})$ much higher than wind turbines can cause.

\subsection{Vibroacoustic Disease}

According to Alves-Pereira and Castelo Branco [112], the infrasound and low-frequency sound of a wind turbine can cause vibroacoustic disease (VAD), an affliction identified by a thickening of the mitral valve (one of the valves in the heart) and the pericardium (a sac containing the heart). The most important data regarding VAD are derived from a study among aircraft technicians who were professionally exposed to high levels of low-frequency sound [119]. VAD is controversial as a syndrome or disease. Results of animal studies have only been obtained in studies using lowfrequency sound levels which are found in industrial settings. No studies are known that use a properly selected control group. And finally, the way the disease was diagnosed has been criticized because of a lack of precision [120]

After investigating a family with two wind turbines at 322 and $642 \mathrm{~m}$ from their dwelling, Alves-Pereira and Castelo Branco [112] concluded that VAD occurred and was caused by low-frequency sound. The measured sound levels were substantially lower ( $20 \mathrm{~dB}$ or more) than levels at which VAD was thought to occur by Marciniak et al. [119] and the levels were below the normal hearing threshold for a considerable range of frequencies in this range. In their review of evidence on VAD Chapman et al. [93] concluded that in the scientific community VAD was only supported by the group who coined the term and there is no evidence that vibroacoustic disease is associated with or caused by wind turbines.

\subsection{Effect of Vibrations}

Vibrations from wind turbines can lead to ground vibrations and these can be measured with sensitive vibrations sensors. In several studies vibrations have been measured at large distances, but this was because these vibrations could affect the performance of seismic stations that detect nuclear tests. These vibrations are too weak to be detected or to affect humans, even for people living close to wind turbines [98].

In measurements at three dwellings, Cooper et al. [104] found surges in ground vibration near wind turbines that were associated with wind gusts, outside as well as inside one of the three houses. Vibration levels were weak (less than from people moving around), but measurable. According to Cooper, two residents were clearly more sensitive than the other four; the sensations experienced by the residents seemed to be more related to a reaction to the operation of the wind turbines than to the sound or vibration of the wind turbines. This echoes earlier findings from Kelley [121] who investigated complaints, from two residences, that were thought to be associated with strong low-frequency sound pulses from the experimental downwind MOD-1 wind turbine. The low-frequency sound pulses were generated when a turbine blade passed the wind wake behind the mast. The 
residents perceived 'audible and other sensations, including vibration and sensed pressure changes'. Although the wind turbine sound at frequencies below about $30 \mathrm{~Hz}$ was below the normal hearing threshold, this sound was believed to be causing the annoyance complaints. The sound levels were within a range of sound levels and frequencies cited in a report from Stephens et al. [122] for situations where (subaudible) industrial sound within this range was believed to be the source of the complaints. This could be explained by the response of a building to the sound outside: the distribution of sound pressure in the building can be the result of structure-borne sound, standing waves and resonances due to the configuration of a room, closet and/or hallway. The rhythmic character of wind turbine sound could have an added effect because of the periodic pressure pulses; if these coincide with a structural resonance of the building the indoor level can be higher than expected from just reduction by the facade. These structural vibrations can lead to sound at higher frequencies which are audible. Several authors have pointed out that the rhythmic character itself (technically, amplitude modulation) is more relevant to human perception than low-frequency sound or infrasound (see What makes wind turbine sound so annoying? in Sect. 3.1.1). However, the appreciation of the sound may depend on a combination of the frequency and strength of the modulation and the balance of low- and higher-frequency components [123].

\section{Discussion and Conclusions}

\subsection{Primary Findings}

This review summarizes the findings of ten previous reviews on the effect of wind turbines on health and the role of personal, situational and physical factors other than sound. In addition, the results from 22 papers that were published later (after early 2015) were reviewed. The results will be presented here with an indication of a possible change over time when comparing evidence before and since 2015 .

Results confirm the earlier evidence that living in areas with wind turbines is associated with an increased percentage of highly annoyed residents. Earlier findings of a possible association with perceived and measured sleep disturbances are not confirmed in the latest studies, nor does recent evidence support the notion of a possibly decreased quality of life in relation to exposure to wind turbine sound. Also, the findings of recent studies do not support a relation between subjective and objective stress indicators and exposure to wind turbine sound. Earlier findings on personal, situational and contextual factors (such as visual aspects, attitude, benefits, perceived injustice and fair planning process) are confirmed in the most recent studies. Available scientific research does not provide a definite answer about the question whether wind turbine sound can cause health effects which are different from those of other sound sources. However, wind turbines do stand out because of their rhythmic character, both visually and aurally. Several new laboratory studies have in particular addressed the role of amplitude modulation (AM). Results are inconclusive regarding the effect of amplitude modulation on annoyance. A common conclusion seems to be that AM appears to aggravate existing annoyance, but does not lead to annoyance in persons who benefit from or have a positive attitude towards wind turbines. Recent reviews of McCunney et al. [25] and Harrisson [27] conclude that there is no scientific evidence to support the hypothesis that wind turbine infrasound and low-frequency sound have effects that other sources do not have. In general, evidence on specific health effects of low-frequency sound is limited. As the CCA [28] worded it: knowledge gaps remain with regard to the influence of specific sound characteristics, such as amplitude modulation, low-frequency content or visual aspects of wind turbines, which are difficult to study in isolation.

The recent studies largely support earlier scientific findings but have improved the state of the art with thorough research and adding objective measures to self-reported effects. Exposure characterization has been improved considerably by including local sound measurements in field studies, and the recent AM studies have improved the knowledge base considerably.

\subsection{Discussion}

\subsubsection{Physical, Social and Personal Factors Add}

There are many models or schemes that show how people react to sound. However, much of the public debate about wind turbines and sound is at the planning stage when wind turbines are not yet present. Michaud et al. [63] proposed a model that incorporates the influence of (media) information and expectations as well as actual wind turbine sound exposure. In Fig. 3 we present a simplified model based on the one from Michaud et al. [63]. It shows that plans for wind turbines or actual wind turbines can lead to disturbances and concern, but a number of factors can influence the effect of the (planned) turbines (see 'Michaud model' for these factors). Personal factors include attitude, expectations, noise sensitivity. Situational factors include other possible impacts such as visibility or shadow flicker, other sound sources, type of area. Contextual factors include participation, the decisionmaking process, the siting procedure, procedural justice.

The model illustrates that next to wind turbine sound itself, several other features are relevant for residents living in the vicinity of wind turbines. These include physical and personal aspects, and the particular circumstances around decision-making and siting of a wind farm as well as commu- 


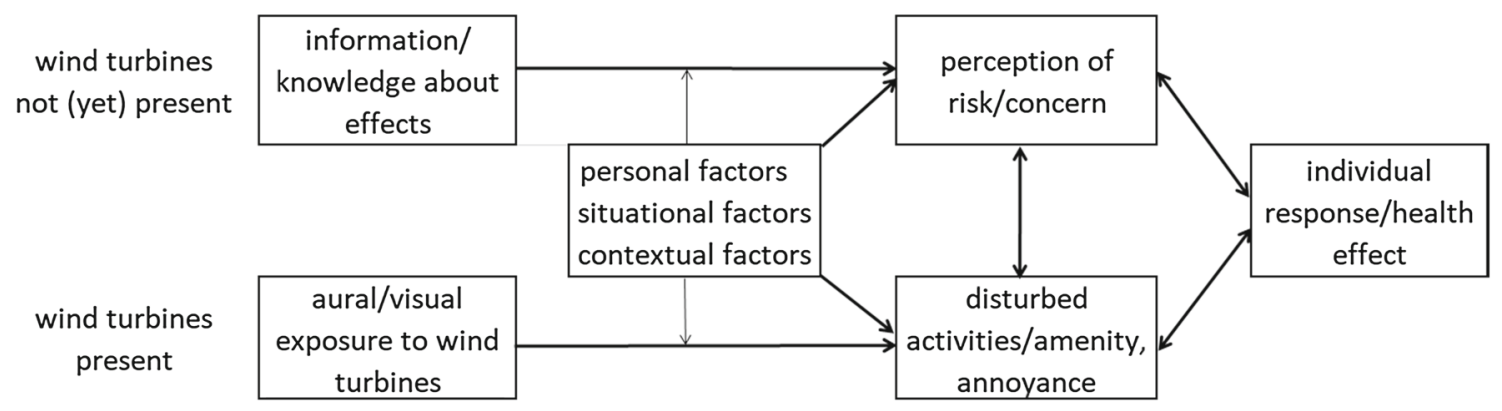

Fig. 3 A graphic summary model for the relationship between exposure to wind turbines and individual response (after Michaud et al. [63])

nication and the relation between different people involved in the process. There is consensus that visual aspects play a key role in reactions to wind turbines and this includes the (mis-)match with the landscape, shadow casting and blinking lights. Shadow casting from wind turbines is described as annoying for people and also the movement of the rotor blades themselves can be experienced as disturbing. Light reflection/flicker from the blades and vibrations play a minor role in modern turbines as far as the effect on residents is concerned. It has been shown that people who benefit from and/or have a positive attitude towards wind turbines in their environment in general report less annoyance. People who perceive wind turbines as intruding into their privacy and detrimental to the quality of their living environment in general report more annoyance. Perceived (procedural) injustice has been found to be related with the feeling of intrusion and lack of control/helplessness. Most studies confirm the role of noise sensitivity in the reaction to wind turbines, independent of the sound level or sound characteristics. Attitude and media coverage are just a few elements of the complex process of policy and decision-making for siting wind turbines. Most recent studies conclude that social acceptance of wind projects is highly dependent on a fair planning process and local involvement. The latest evidence seems to confirm the role of these factors described in earlier reviews and studies.

\subsubsection{Evidence on Adverse Effects of Wind Turbine Sound}

Noise annoyance is the main health effect associated with the exposure to sound from an operational wind turbine. At equal sound levels, sound from wind turbines is experienced as more annoying than that of traffic sources [19,29]. From epidemiological and laboratory studies, the typical character of wind turbine sound comes forward as one of the key issues. Particularly, the rhythmic character of the sound (technically, amplitude modulation or AM), described as a swishing or wooshing sound, is experienced as annoying. Residential wind turbine sound levels themselves are modest when compared to those from other sources such as road or industrial sound. However, recent laboratory studies [12,71,72] are inconclusive regarding the effect of amplitude modulation on annoyance. One conclusion is that 'there is a strong possibility that amplitude modulation is the main cause of the properties of wind turbine noise', in which properties refer to sounds that are easily detectable and highly annoying at relatively low sound levels [12]. Another dismisses amplitude modulation as a negative factor per se because it is highly related to attitude [72]. A common factor is that AM appears to aggravate existing annoyance, but does not lead to annoyance for persons positive about or benefiting from wind turbines. The general exposure-effect relation for annoyance from wind turbine sound includes all aspects that influence annoyance and thus averages over all local situations and non-acoustic factors. The relation can therefore only form an indication of the annoyance levels to be expected in a local situation.

New evidence regarding the effect of night time wind turbine sound exposure on sleep suggests no direct effect, but remains inconclusive. The current results do not allow a definite conclusion regarding both subjective and objective sleep indicators [62]. However, studies do find a relationship between self-reported sleep disturbance and annoyance from wind turbines [41] and between self-reported sleep disturbance and perceived quality of life $[47,48]$.

For other health effects, there is insufficient evidence for a direct relation with wind turbine sound levels.

Based on noise research in general, we can conclude that chronic annoyance from wind turbines and the feeling that the quality of the living environment has deteriorated or will do so in the future, and can have a negative impact on well-being and health in people living in the vicinity of wind turbines. This is similar to the effect of other stressors [19]. The moderate effect of the level of wind turbine sound on annoyance and considering the range of factors that influence the levels of annoyance implies that reducing the impact of wind turbine sound will profit from considering other factors associated with annoyance. The influence of these factors is not necessarily unique for wind turbines. The fact that residents can respond very differently to a sound shows that annoyance from a sound is not inextricably bound up with that sound. 


\subsubsection{Evidence on Adverse Effects of Low-Frequency Sound and Infrasound}

There is substantial knowledge about the physical aspects of low-frequency sound. Low-frequency sound can be heard daily from road and air traffic and many other sources. Less is known about infrasound and certainly the perception of infrasound. Infrasound can sometimes be heard, e.g. from big machines and storms, but is not as common as low-frequency or 'normal' sound. However, with sensitive equipment infrasound, as well as vibrations, can be measured at large distances. Infrasound and low-frequency sound are present in wind turbine sound. Low-frequency sound is included in most studies as part of the normal sound range. In contrast, infrasound is in most studies considered as inaudible as the level of infrasound is low with respect to human sensitivity. Studies of the perception of wind turbine infrasound support this. Infrasound and low-frequency sound from wind turbines have been suggested to pose unique health hazards. There is little scientific evidence to support this. The levels of infrasound involved are comparable to the level of internal body sounds and pressure variations at the ear while walking. Infrasound from wind turbines is not loud enough to influence the sense of balance (i.e. activate the vestibular system), except perhaps for persons with a specific hearing condition (SCDS). Effects such as dizziness and nausea, or motion sickness, could be an effect of infrasound, but are expected at much higher levels than wind turbines produce in residential situations. Vibroacoustic disease and the wind turbine syndrome are controversial and scientifically not supported. At the present levels of wind turbine sound, the alleged occurrence of vibroacoustic disease (VAD) or the disease (VVVD) causing the wind turbine syndrome (WTS) is unproven and unlikely. However, the symptoms associated with WTS are symptoms found in relation to stress.

The rhythmic character of wind turbine sound is caused by a succession of sound pulses produced by the blade rotations. From early research it was concluded that this may lead to structural vibrations of a house and wind turbines thus may be perceived indirectly inside a house and hence lead to annoyance. This possibility needs further investigation.

\subsection{Strengths and Limitations}

The strengths of this review are the use of a robust search strategy to identify relevant studies, its broad approach in terms of both the range of outcomes and noise characteristics considered and the special consideration of the role of low-frequency sound and infrasound. We also tried to make the available knowledge accessible for a broader audience by avoiding technical terms as much as possible. We added to earlier reviews by reviewing the latest studies which are of high quality and have shown how the state of knowledge developed over time. However, we recognize limitations as well. Although the literature search was performed systematically, the review is primarily a narrative one and in this sense will repeat in a less rigid manner the conclusions of previous reviews. Although the studies were systematically selected and structured, in our wording and interpretation we follow a 'story line' inherent to a narrative review. The text reflects our view, based on an extensive amount of knowledge of (reactions to) wind turbine sound and environmental sound in general.

\subsection{Methodological Considerations and Implications for Future Research}

Again, or we might say still, we can conclude that the earlier identified lack of methodological and statistical strength of wind turbine studies by CCA [28] still holds. With a few exceptions in general, the sample size of most studies is limited, and with regard to both the exposure and outcomes, there is room for improvement.

\subsection{Final Conclusion}

Systematic reviews published since 2009 including some recent and high quality ones, and new evidence not yet reviewed suggest that exposure to wind turbine sound is associated with higher odds for annoyance. The proximity of a wind turbine or wind farm has not conclusively been proven to negatively affect stress responses, quality of life, sleep quality (subjective and objective) nor other health complaints. A reason for this may be that individual traits and attitudes, visual aspects as well as the process of wind farm planning and decision-making are highly likely to influence the response to sound from wind turbines. Larger-scale studies at locations with varying circumstances and with a before after component (prospective cohort) are recommended for the future. Ideally measured sound levels over the whole frequency range and routinely collected registry health data should be used in conjunction with more subjective data.

Acknowledgements The basis for this text is a report that was written at the request of the Noise and NIR Division of the Swiss Federal Office for the Environment (Bundesamt für Umwelt). We thank Professor Geoff Leventhall and Professor Kerstin Persson Waye as well as Dr. Mark Brink for their useful comments to earlier versions of this manuscript.

\section{References}

1. Onakpoya, I.J., O'Sullivan, J., Thompson, M.J., Heneghan, C.J.: The effect of wind turbine noise on sleep and quality of life: a systematic review and meta-analysis of observational studies. Environ. Int. 30(82), 1-9 (2015) 
2. WHO: WHO Constitution Adopted by the International Health Conference held in New York from 19 June to 22 July 1946, Signed on 22 July 1946 by the Representatives of 61 States (Off. Rec. Wld Hlth Org., 2, 100), and Entered into Force on 7 April 1948. WHO, (1948)

3. WHO: Burden of disease from environmental noise Quantification of healthy life years lost in Europe. In: Lin Fritschi, A., Lex, B., Rokho, K., Dietrich, S., Stelios, K. (eds) WHO regional office for Europe. JRC. ISBN:978 9289002295 (1948)

4. Hurtley, C. (ed.): Night Noise Guidelines for Europe. WHO Regional Office Europe, Copenhagen (2009)

5. Wagner, S., Bareiss, R., Guidati, G.: Wind Turbine Noise. Springer, Berlin (2012)

6. Van den Berg, G.P.: The sound of high winds. The effect of atmospheric stability on wind turbine sound and microphone noise. 2006. ACADEMIC thesis, University of Groningen (2006)

7. Leventhall, G., Bowdler, D.: Wind Turbine Noise: How it is Produced, Propagated Measured and Received. Multi-Science Publishing, Brentwood (2011)

8. Nobbs, B., Doolan, C.J., Moreau, D.J.: Characterisation of noise in homes affected by wind turbine noise. In: Proceedings of Acoustics (2012)

9. Stigwood, M., Large, S.: Audible amplitude modulation-results of field measurements and investigations compared to psychoacoustical assessment and theoretical research. In: Fifth International Conference on Wind Turbine Noise (2013)

10. Larsson, C., Öhlund, O.: Amplitude modulation of sound from wind turbines under various meteorological conditions. J. Acoust. Soc. Am. 135(1), 67-73 (2014)

11. Cand, M., Bullmore, A., Smith, M., Von-Hunerbein, S., Davis, R.: Wind turbine amplitude modulation: research to improve understanding as to its cause and effect. In: Acoustics 2012, 23 (2012)

12. Yoon, K., Gwak, D.Y., Seong, Y., Lee, S., Hong, J., Lee, S.: Effects of amplitude modulation on perception of wind turbine noise. J. Mech. Sci. Technol. 30(10), 4503-9 (2016)

13. Yokoyama, S., Sakamoto, S., Tachibana, H.: Perception of low frequency components in wind turbine noise. Noise Control Eng. J. 62(5), 295-305 (2014)

14. Van den Berg, F.: Criteria for wind farm noise: Lmax and Lden. In: Proceedings of the Acoustics'08, Paris (2008)

15. Søndergaard, B.: Low frequency noise from wind turbines: do the danish regulations have any impact? An analysis of noise measurements. Int. J. Aeroacoust. 14(5-6), 909-915 (2015)

16. Møller, H., Pedersen, C.S.: Low-frequency noise from large wind turbines. J. Acoust. Soc. Am. 129(6), 3727-44 (2011)

17. Van Kamp, I., Dusseldorp, A., van den Berg, G.P., Hagens, W.I., Slob, M.J.: Windturbines: invloed op de beleving en gezondheid van omwonenden: GGD informatieblad medische milieukunde Update 2013. RIVM briefrapport 200000001. In: Dutch (2014)

18. Windenergie: Pilot Kennisplatform. "Geluid van windturbines." (RIVM, 2015). In: Dutch (2015)

19. Merlin, T., Newton, S., Ellery, B., Milverton, J., Farah, C.: Systematic review of the human health effects of wind farms. National Health \& Medical Research Council, Canberra (2013)

20. Public health effects of siting and operating onshore wind turbines. Publication of the Superior Health Council (SHC) no. 8738, Brussels. www.tinyurl.com/SHC-8738-windturbines

21. Knopper, L.D., Ollson, C.A.: Health effects and wind turbines: a review of the literature. Environ. Health 10(1), 78 (2011)

22. Ellenbogen, J.M., Grace, S., Heiger-Bernays, W.J., Manwell, J.F., Mills, D.A., Sullivan, K.A., Santos, S.L.: Wind Turbine Health Impact Study. Report of Independent Expert Panel. Prepared for: Massachusetts Department of Environmental Protection. Massachusetts Department of Health (2012)
23. MDEP: Massachusetts Department of Environmental Protection and Massachusetts Department of Public Health. Wind Turbine Health Impact Study: Report of Independent Expert Panel (2012)

24. Schmidt, J.H., Klokker, M.: Health effects related to wind turbine noise exposure: a systematic review. PLoS ONE 9(12), e114183 (2014)

25. McCunney, R.J., Mundt, K.A., Colby, W.D., Dobie, R., Kaliski, K., Blais, M.: Wind turbines and health: a critical review of the scientific literature. J. Occup. Environ. Med. 56(11), e108-30 (2014)

26. Knopper, L.D., Ollson, C.A., McCallum, L.C., Whitfield Aslund, M.L., Berger, R.G., Souweine, K., McDaniel, M.: Wind turbines and human health. Front. Public Health 19(2), 63 (2014)

27. Harrison, R.V.: On the biological plausibility of wind turbine syndrome. Int. J. Environ. Health Res. 25(5), 463-8 (2015)

28. Council of Canadian Academies, 2015: Understanding the Evidence: Wind Turbine Noise. Ottawa $(\mathrm{ON})$ : The Expert Panel on Wind Turbine Noise and Human Health. Council of Canadian Academies (2015)

29. Janssen, S.A., Vos, H., Eisses, A.R., Pedersen, E.: A comparison between exposure-response relationships for wind turbine annoyance and annoyance due to other noise sources. J. Acoust. Soc. Am. 130(6), 3746-53 (2011)

30. Yano, T., Kuwano, S., Kageyama, T., Sueoka, S., Tachibana, H.: Dose-response relationships for wind turbine noise in Japan. In: Proceedings of the Inter-noise (2013)

31. Pawlaczyk-Łuszczyńska, M., Dudarewicz, A., Zaborowski, K., Zamojska-Daniszewska, M., Waszkowska, M.: Evaluation of annoyance from the wind turbine noise: a pilot study. Int. J. Occup. Med. Environ. Health 27(3), 364-88 (2014)

32. Babisch, W., Pershagen, G., Selander, J., Houthuijs, D., Breugelmans, O., Cadum, E., Vigna-Taglianti, F., Katsouyanni, K., Haralabidis, A.S., Dimakopoulou, K., Sourtzi, P.: Noise annoyance-a modifier of the association between noise level and cardiovascular health? Sci. Total Environ. 1(452), 50-7 (2013)

33. Miedema, H.M., Vos, H.: Noise annoyance from stationary sources: relationships with exposure metric day-evening-night level (DENL) and their confidence intervals. J. Acoust. Soc. Am. 116(1), 334-43 (2004)

34. Miedema, H.M., Oudshoorn, C.G.: Annoyance from transportation noise: relationships with exposure metrics DNL and DENL and their confidence intervals. Environ. Health Perspect. 109(4), 409 (2001)

35. Fiumicelli, D.: Windfarm noise dose-response: a literature review. Acoust. Bull. 64, 26-34 (2011)

36. Michaud, D.S., Keith, S.E., Feder, K., Voicescu, S.A., Marro, L., Than, J., Guay, M., Bower, T., Denning, A., Lavigne, E., Whelan, C.: Personal and situational variables associated with wind turbine noise annoyance. J. Acoust. Soc. Am. 139(3), 1455-66 (2016)

37. Van den Berg, F., Pedersen, E., Bouma, J., Bakker, R.: Visual and acoustic impact of wind turbine farms on residents. Final Rep. 3, 63 (2008)

38. Persson Waye, K., Öhrström, E.: Psycho-acoustic characters of relevance for annoyance of wind turbine noise. J. Sound Vib. 250(1), 65-73 (2002)

39. Hayes, M.: The measurement of low frequency noise at three UK wind farms. Contract Number W/45/00656/00/00, URN 6, 1412 (2006)

40. Large, S., Stigwood, M.: The noise characteristics of compliant wind farms that adversely affect its neighbours. In: INTERNOISE and NOISE-CON Congress and Conference Proceedings 2014 Oct 14, vol. 249, No. 1, pp. 6269-6288. Institute of Noise Control Engineering (2014)

41. Bakker, R.H., Pedersen, E., van den Berg, G.P., Stewart, R.E., Lok, W., Bouma, J.: Impact of wind turbine sound on annoyance, self-reported sleep disturbance and psychological distress. Sci. Total Environ. 15(425), 42-51 (2012) 
42. Pedersen, E., Persson, W.K.: Wind turbine noise, annoyance and self-reported health and well-being in different living environments. Occup. Environ. Med. 64(7), 480-6 (2007)

43. Qu, F., Tsuchiya, A., Kang, J.: Impact of noise from suburban wind turbines on human well-being. In: Proceedings 7th International Conferences on Wind Turbine Noise, Rotterdam (2017)

44. Van den Berg, F.: Effects of sound on people. In: Leventhall, G., Bowdler, D. (eds.) Wind Turbine Noise. Multi-Science Publishing, Brentwood (2011)

45. Canadian Summary. http://www.hc-sc.gc.ca/ewh-semt/ noise-bruit/turbine-eoliennes/summary-resume-eng.php (2014)

46. Van den Berg, F., Verhagen, C., Uitenbroek, D.: The relation between scores on noise annoyance and noise disturbed sleep in a public health survey. Int. J. Environ. Res. Public Health 11(2), 2314-27 (2014)

47. Shepherd, D., McBride, D., Welch, D., Dirks, K.N., Hill, E.M.: Evaluating the impact of wind turbine noise on health-related quality of life. Noise Health 13(54), 333 (2011)

48. Nissenbaum, M.A., Aramini, J.J., Hanning, C.D.: Effects of industrial wind turbine noise on sleep and health. Noise Health 14(60), 237 (2012)

49. Van Kamp, I., Lam, K.C., Brown, A.L., Wong, T.W., Law, C.W.: Sleep-disturbance and quality of sleep in Hong Kong in relation to night time noise exposure. J. Acoust. Soc. Am. 131(4), 3222 (2012)

50. Thorne, B.: the relevance of the precautionary principle to wind farm noise planning. In: INTER-NOISE and NOISE-CON Congress and Conference Proceedings 2014 Oct 14, vol. 249, No. 3, pp. 4065-4074. Institute of Noise Control Engineering (2014)

51. Dusseldorp, A., Houthuijs, D., van Overveld, A., van Kamp, I., Marra, M.: Handreiking geluidhinder wegverkeer: Berekenen en meten. RIVM rapport 609300020. 2011 Oct 28. In: Dutch (2011)

52. Pedersen, E., Hallberg, L.M., Persson, W.K.: Living in the vicinity of wind turbines-a grounded theory study. Qual. Res. Psychol. 4(1-2), 49-63 (2007)

53. Van Kamp, I., Davies, H.: Noise and health in vulnerable groups: a review. Noise Health 15(64), 153 (2013)

54. Miedema, H.M., Vos, H.: Noise sensitivity and reactions to noise and other environmental conditions. J. Acoust. Soc. Am. 113(3), 1492-504 (2003)

55. Gross, C.: Community perspectives of wind energy in Australia: the application of a justice and community fairness framework to increase social acceptance. Energy Policy 35(5), 2727-36 (2007)

56. Tyler, T.R.: Social justice: outcome and procedure. Int. J. Psychol. 35(2), 117-25 (2000)

57. Wolsink, M.: Maatschappelijke acceptatie van windenergie Thesis Publishers, Amsterdam (1990)

58. Breukers, S.: Institutional capacity building for wind power. A geographical comparison. Ph.D. thesis, University of Amsterdam (2007)

59. Devine-Wright, P., Howes, Y.: Disruption to place attachment and the protection of restorative environments: a wind energy case study. J. Environ. Psychol. 30(3), 271-80 (2010)

60. Walker, G., Devine-Wright, P.: Community renewable energy: what should it mean? Energy Policy 36(2), 497-500 (2008)

61. Michaud, D.S., Feder, K., Keith, S.E., Voicescu, S.A., Marro, L., Than, J., Guay, M., Denning, A., McGuire, D.A., Bower, T., Lavigne, E.: Exposure to wind turbine noise: perceptual responses and reported health effects. J. Acoust. Soc. Am. 139(3), 1443-54 (2016)

62. Michaud, D.S., Feder, K., Keith, S.E., Voicescu, S.A., Marro, L., Than, J., Guay, M., Denning, A., Murray, B.J., Weiss, S.K., Villeneuve, P.J.: Effects of wind turbine noise on self-reported and objective measures of sleep. Sleep 39(1), 97 (2016)

63. Michaud, D.S., Feder, K., Keith, S.E., Voicescu, S.A., Marro, L., Than, J., Guay, M., Denning, A., Bower, T., Villeneuve, P.J.,
Russell, E.: Self-reported and measured stress related responses associated with exposure to wind turbine noise. J. Acoust. Soc. Am. 139(3), 1467-79 (2016)

64. Feder, K., Michaud, D.S., Keith, S.E., Voicescu, S.A., Marro, L., Than, J., Guay, M., Denning, A., Bower, T.J., Lavigne, E., Whelan, C.: An assessment of quality of life using the WHOQOL-BREF among participants living in the vicinity of wind turbines. Environ. Res. 31(142), 227-38 (2015)

65. Voicescu, S.A., Michaud, D.S., Feder, K., Marro, L., Than, J., Guay, M., Denning, A., Bower, T., van den Berg, F., Broner, N., Lavigne, E.: Estimating annoyance to calculated wind turbine shadow flicker is improved when variables associated with wind turbine noise exposure are considered. J. Acoust. Soc. Am. 139(3), 1480-92 (2016)

66. Kageyama, T.: Adverse effects of community noise as a public health issue. Sleep Biol. Rhythms 14(3), 223-229 (2016)

67. Kageyama, T., Yano, T., Kuwano, S., Sueoka, S., Tachibana, H.: Exposure-response relationship of wind turbine noise with selfreported symptoms of sleep and health problems: a nationwide socio-acoustic survey in Japan. Noise Health 18(81), 53 (2016)

68. Abbasi, M., Monazzam, M.R., Ebrahimi, M.H., Zakerian, S.A., Dehghan, S.F., Akbarzadeh, A.: Assessment of noise effects of wind turbine on the general health of staff at wind farm of Manjil, Iran. J. Low Freq. Noise Vib. Act. Control 35(1), 91-8 (2016)

69. Blanes-Vidal, V., Schwartz, J.: Wind turbines and idiopathic symptoms: the confounding effect of concurrent environmental exposures. Neurotoxicol. Teratol. 55, 50-57 (2016)

70. Schäffer, B., Schlittmeier, S.J., Pieren, R., Heutschi, K., Brink, M., Graf, R., Hellbrück, J.: Short-term annoyance reactions to stationary and time-varying wind turbine and road traffic noise: a laboratory study a. J. Acoust. Soc. Am. 139(5), 2949-63 (2016)

71. Crichton, F., Petrie, K.J.: Health complaints and wind turbines: the efficacy of explaining the nocebo response to reduce symptom reporting. Environ. Res. 31(140), 449-55 (2015)

72. Ioannidou, C., Santurette, S., Jeong, C.H.: Effect of modulation depth, frequency, and intermittence on wind turbine noise annoyance a. J. Acoust. Soc. Am. 139(3), 1241-51 (2016)

73. Hafke-Dys, H., Preis, A., Kaczmarek, T., Biniakowski, A., Kleka, P.: Noise annoyance caused by amplitude modulated sounds resembling the main characteristics of temporal wind turbine noise. Arch. Acoust. 41(2), 221-32 (2016)

74. Tonin, R., Brett, J., Colagiuri, B.: The effect of infrasound and negative expectations to adverse pathological symptoms from wind farms. J. Low Freq. Noise Vib. Act. Control 35(1), 77-90 (2016)

75. Maffei, L., Masullo, M., Gabriele, M.D., Votsi, N.E., Pantis, J.D., Senese, V.P.: Auditory recognition of familiar and unfamiliar subjects with wind turbine noise. Int. J. Environ. Res. Public Health 12(4), 4306-20 (2015)

76. Jalali, L., Bigelow, P., Nezhad-Ahmadi, M.R., Gohari, M., Williams, D., McColl, S.: Before-after field study of effects of wind turbine noise on polysomnographic sleep parameters. Noise Health 18(83), 194 (2016)

77. Jalali, L., Bigelow, P., McColl, S., Majowicz, S., Gohari, M., Waterhouse, R.: Changes in quality of life and perceptions of general health before and after operation of wind turbines. Environ. Pollut. 30(216), 608-15 (2016)

78. Jalali, L., Nezhad-Ahmadi, M.R., Gohari, M., Bigelow, P., McColl, S.: The impact of psychological factors on self-reported sleep disturbance among people living in the vicinity of wind turbines. Environ. Res. 31(148), 401-10 (2016)

79. Krekel, C., Zerrahn, A.: Does the presence of wind turbines have negative externalities for people in their surroundings? Evidence from well-being data. J. Environ. Econ. Manag. 31(82), 221-38 (2017) 
80. Botterill, L.C., Cockfield, G.: The relative importance of landscape amenity and health impacts in the wind farm debate in Australia. J. Environ. Policy Plan. 18(4), 447-62 (2016)

81. Takashi, Y., Kuwano, S., Tachibana, H.: The visual effects of wind turbines in Japan. In: Proceedings 7th International Conference on Wind Turbine Noise, Rotterdam (2017)

82. Keith, S.E., Feder, K., Voicescu, S.A., Soukhovtsev, V., Denning, A., Tsang, J., Broner, N., Leroux, T., Richarz, W., van den Berg, F.: Wind turbine sound pressure level calculations at dwellings. J. Acoust. Soc. Am. 139(3), 1436-42 (2016)

83. Keith, S.E., Feder, K., Voicescu, S.A., Soukhovtsev, V., Denning, A., Tsang, J., Broner, N., Richarz, W., van den Berg, F.: Wind turbine sound power measure-ments. J. Acoust. Soc. Am. 139(3), 1431-1435 (2016)

84. Van Renterghem, T., Bockstael, A., De Weirt, V., Botteldooren, D.: Annoyance, detection and recognition of wind turbine noise. Sci. Total Environ. 1(456), 333-45 (2013)

85. Pedersen, E., van den Berg, F., Bakker, R., Bouma, J.: Response to noise from modern wind farms in The Netherlands. J. Acoust. Soc. Am. 126(2), 634-43 (2009)

86. Blackburn, D., Rodrigue, L., Tardif, I., Chagnon, M., Martel, K., Morasse, A., et al.: Éoliennes et santé publique. Synthèse des connaissances. Québec: Institut National de Santé Publique de Québec; 2009 Septembre. http://www.inspq.qc.ca/publications/ notice.asp?E=p\&NumPublication=1015. Accessed 09 Feb 2013 (2013)

87. Pasqualetti, M.J.: Social barriers to renewable energy landscapes. Geogr. Rev. 101(2), 201-23 (2011)

88. Pedersen, E., Larsman, P.: The impact of visual factors on noise annoyance among people living in the vicinity of wind turbines. J. Environ. Psychol. 28(4), 379-89 (2008)

89. Kroesen, M., Molin, E.J., van Wee, B.: Testing a theory of aircraft noise annoyance: a structural equation analysis. J. Acoust. Soc. Am. 123(6), 4250-60 (2008)

90. Bartels, S., Márki, F., Müller, U.: The influence of acoustical and non-acoustical factors on short-term annoyance due to aircraft noise in the field - the COSMA study. Sci. Total Environ. 15(538), 834-43 (2015)

91. Fyhri, A., Klæboe, R.: Road traffic noise, sensitivity, annoyance and self-reported health - a structural equation model exercise. Environ. Int. 35(1), 91-7 (2009)

92. Park, S.H., Lee, P.J., Yang, K.S., Kim, K.W.: Relationships between non-acoustic factors and subjective reactions to floor impact noise in apartment buildings. J. Acoust. Soc. Am. 139(3), 1158-67 (2016)

93. Chapman, S., George, A.S., Waller, K., Cakic, V.: The pattern of complaints about Australian wind farms does not match the establishment and distribution of turbines: support for the psychogenic, 'communicated disease' hypothesis. PLoS ONE 8(10), e76584 (2013)

94. Crichton, F., Dodd, G., Schmid, G., Gamble, G., Petrie, K.J.: Can expectations produce symptoms from infrasound associated with wind turbines? Health Psychol. 33(4), 360 (2014)

95. Hatfield, J., Job, R.S., Hede, A.J., Carter, N.L., Peploe, P., Taylor, R., Morrell, S.: Human response to environmental noise: the role of perceived control. Int. J. Behav. Med. 1(9(4)), 341-359 (2002)

96. White, K., Hofman, W.F., van Kamp, I.: Noise sensitivity in relation to baseline arousal, physiological response and psychological features to noise exposure during task performance. In: INTERNOISE and NOISE-CON Congress and Conference Proceedings 2010 Jun 13, vol. 2010, No. 9, pp. 2604-2610. Institute of Noise Control Engineering (2010)

97. Shepherd, D., Welch, D., Dirks, K.N., Mathews, R.: Exploring the relationship between noise sensitivity, annoyance and health-related quality of life in a sample of adults exposed to envi- ronmental noise. Int. J. Environ. Res. Public Health 7, 3579-94 (2010)

98. Coleby, A.M., Miller, D.R., Aspinall, P.A.: Public attitudes and participation in wind turbine development. J. Environ. Assess. Policy Manag. 11(01), 69-95 (2009)

99. Zaunbrecher, B.S., Ziefle, M.: Integrating acceptance-relevant factors into wind power planning: a discussion. Sustain. Cities Soc. 30(27), 307-14 (2016)

100. Enevoldsen, P., Sovacool, B.K.: Examining the social acceptance of wind energy: practical guidelines for onshore wind project development in France. Renew. Sustain. Energy Rev. 31(53), 17884 (2016)

101. Walker, C., Baxter, J., Ouellette, D.: Adding insult to injury: the development of psychosocial stress in Ontario wind turbine communities. Soc. Sci. Med. 31(133), 358-65 (2015)

102. Salt, A.N., Hullar, T.E.: Responses of the ear to low frequency sounds, infrasound and wind turbines. Hear. Res. 268(1), 12-21 (2010)

103. Baliatsas, C., van Kamp, I., van Poll, R., Yzermans, J.: Health effects from low-frequency noise and infrasound in the general population: is it time to listen? A systematic review of observational studies. Sci. Total Environ. 1(557), 163-9 (2016)

104. Cooper, K., Kirkpatrick, P., Stewart, A.: Health effects associated with working in the wind power generation industry: a comprehensive systematic review. JBI Database Syst. Rev. Implement. Rep. 12(11), 327-73 (2014)

105. Berger, R.G., Ashtiani, P., Ollson, C.A., Aslund, M.W., McCallum, L.C., Leventhall, G., Knopper, L.D.: Health-based audible noise guidelines account for infrasound and low-frequency noise produced by wind turbines. Front. Public Health. 3, 31 (2015)

106. Moller, H., Pedersen, C.S.: Hearing at low and infrasonic frequencies. Noise Health 6(23), 37 (2004)

107. Leventhall, G.: Infrasound and the ear. In: Proceedings 5th International Conference on Wind Turbine Noise (2013)

108. Bolin, K., Bluhm, G., Eriksson, G., Nilsson, M.E.: Infrasound and low frequency noise from wind turbines: exposure and health effects. Environ. Res. Lett. 6(3), 035103 (2011)

109. Herrmann, L., Bayer, O., Krapf, K.G., Hoffmann, M., Blaul, J., Mehnert, C.: Low-frequency noise incl. infrasound from wind turbines and other sources. In: INTER-NOISE and NOISE-CON Congress and Conference Proceedings 2016 Aug 21, vol. 253, No. 3, pp. 5580-5589. Institute of Noise Control Engineering (2016)

110. Frey, B.J., Hadden, P.J.: Noise radiation from wind turbines installed near homes: effects on health. With an annotated review of the research and related issues

111. Pierpont, N.: Wind Turbine Syndrome: A Report on a Natural Experiment. K-Selected Books, Santa Fe (2009)

112. Alves-Pereira, M., Branco, N.A.: Vibroacoustic disease: biological effects of infrasound and low-frequency noise explained by mechanotransduction cellular signalling. Prog. Biophys. Mol. Biol. 93(1), 256-79 (2007)

113. Salt, A.N., Kaltenbach, J.A.: Infrasound from wind turbines could affect humans. Bull. Sci. Technol. Soc. 31(4), 296-302 (2011)

114. Farboud, A., Crunkhorn, R., Trinidade, A.: Wind turbine syndrome: fact or fiction? J. Laryngol. Otol. 127(3), 222-6 (2013)

115. Stead, M., Cooper, J., Evans, T.: Comparison of infrasound measured at peoples ears when walking to that measured near windfarms. Acoust. Aust. 42(3), 197-203 (2014)

116. Witthöft, M., Rubin, G.J.: Are media warnings about the adverse health effects of modern life self-fulfilling? An experimental study on idiopathic environmental intolerance attributed to electromagnetic fields (IEI-EMF). J. Psychosom. Res. 74(3), 206-12 (2013)

117. Schomer, P.D., Erdreich, J., Pamidighantam, P.K., Boyle, J.H.: A theory to explain some physiological effects of the infrasonic emissions at some wind farm sites. J. Acoust. Soc. Am. 137(3), 1356-65 (2015) 
118. Nussbaum, D.S., Reinis, S.: Some Individual Differences in Human Response to Infrasound. University of Toronto, Toronto (1985)

119. Marciniak, W., Rodriguez, E., Olszowska, K., Atkov, O., Botvin, I., Araujo, A., Pais, F., Soares Ribeiro, C., Bordalo, A., Loureiro, J., Prazeres De Sá, E., Ferreira, D., Castelo Branco, M.S., Castelo Branco, N.A.: Echocardiographic evaluation in 485 aeronautical workers exposed to different noise environments. Aviat. Space Environ. Med. 70(3 Pt 2), 46-53 (1999)

120. ATSDR: Agency for Toxic Substance and Disease Registry: Expert Review of the Vieques Heart Study. Summary Report for the Vieques Heart Study Expert Panel Review. Contract No. 200-2000-10039. www.atsdr.cdc.gov/sites/vieques/heart_study_ summary (2001)
121. Kelley, N.D., McKenna, H.E., Hemphill, R.R., Etter, C.L., Garrelts, R.L., Linn, N.C.: Acoustic Noise Associated with the MOD-1 Wind Turbine: Its Source, Impact, and Control. US Government Printing Office, Washington (1985)

122. Stephens, D.G., Shepherd, K.P., Hubbard, H.H., Grosveld, F.W.: Guide to the Evaluation of Human Exposure to Noise from Large Wind Turbines. NASA Report TM-83288. NASA Langley Research Center, Hampton (1982)

123. Bengtsson, J., Persson Waye, K., Kjellberg, A.: Evaluations of effects due to low-frequency noise in a low demanding work situation. J. Sound Vib. 278, 83-99 (2004) 